Economics Working Paper Series

2016/018

\title{
Individual vs. Group Decision Making: an Experiment on Dynamic Choice under Risk and Ambiguity
}

Enrica Carbone, Konstantinos Georgalos and Gerardo Infante

The Department of Economics

Lancaster University Management School

Lancaster LA1 4YX

UK

(C) Authors

All rights reserved. Short sections of text, not to exceed two paragraphs, may be quoted without explicit permission, provided that full acknowledgement is given. 


\title{
Individual vs. Group Decision Making: an Experiment on
}

\section{Dynamic Choice under Risk and Ambiguity}

\author{
Enrica Carbone, $\quad$ Konstantinos Georgalos, ${ }^{\dagger} \quad$ Gerardo Infante
}

November 9, 2016

\begin{abstract}
This paper focuses on comparing individual and group decision making, in a stochastic inter-temporal problem in two decision environments, namely risk and ambiguity. Using a consumption/saving laboratory experiment, we investigate behaviour in four treatments: (1) individual choice under risk; (2) group choice under risk; (3) individual choice under ambiguity and (4) group choice under ambiguity. Comparing decisions within and between decision environments, we find an anti-symmetric pattern. While individuals are choosing on average closer to the theoretical optimal predictions, compared to groups in the risk treatments, groups tend to deviate less under ambiguity. Within decision environments, individuals deviate more when they choose under ambiguity, while groups are better planners under ambiguity rather than under risk. We argue that the results might be driven by differences in the levels of ambiguity and risk attitudes between individuals and groups, extending the frequently observed pattern of groups behaving closer to risk and ambiguity neutrality, to its dynamic dimension.
\end{abstract}

JEL classification: C91, C92, D11, D91, E21

Keywords: Risk, Ambiguity, Inter-temporal Optimisation, Group Decision Making, Learning, Experiment

\footnotetext{
*Seconda Università di Napoli, 81043, Capua, Italy, $\bowtie$ enrica.carbone@gmail.com, $\mathbf{0}+390823274063$

${ }^{\dagger}$ Department of Economics, Lancaster University Management School, LA1 4YX, Lancaster, U.K. 凶 k.georgalos@lancaster.ac.uk, $\boldsymbol{\sigma}+44$ (0)1524593170

$\ddagger$ School of Economics, University of East Anglia, NR4 7TJ, Norwich, U.K. $\bowtie$ g.infante@uea.ac.uk, $\mathbf{0}+44$ (0)16035 91731

§Financial support from the MIUR- PRIN 2007 “Consumo, Risparmio e Mercati finanziari: Teorie non Convenzionali, Test e Applicazioni", is gratefully acknowledged.
} 


\section{Introduction}

Most real life economic decisions usually share three main characteristics: (1) the decision environment involves some kind of uncertainty, either objective (risk) or subjective (ambiguity); (2) decisions are made by groups rather than by isolated individuals (e.g. households, executive boards or policy committees) and; (3) decisions involve a sequence of choices over either a long time horizon or after the reception of some relevant information compared of a single choice (e.g. savings, investments or insurance). Standard economic theory relies on the assumption that when an agent is confronted with a stochastic, intertemporal decision problem under uncertainty, she takes into consideration all the possible future states of the world and calculates the optimal solution of this dynamic maximisation problem by applying backward induction, satisfying in that way dynamic consistency (what seems to be optimal at time $t_{2}$ from the viewpoint of $t_{1}$, is still optimal when time $t_{2}$ arrives). On top of that, the majority of economic models make no separation between individual and collective decision making assuming that both act in a behaviourally indistinguishable way.

Recently, a vast body of experimental literature has been devoted to the comparison of individual and group decision making. Two recent reviews of this literature (Charness and Sutter (2012) and Kugler et al. (2012)) conclude that groups tend to behave closer to what is defined as rational choice by economic theory, comply with the predictions of game theoretical models, as well as to decide in a more self-interested manner. Although there is an affluence of studies on collective choice in static frameworks, there is little empirical evidence of group dynamic decision making.

We present evidence from a consumption/saving laboratory experiment where we study choices from two decision units, namely individuals and groups, in two decision environments, risk and ambiguity. We therefore investigate behaviour in four treatments: (1) individual choice under risk; (2) group choice under risk; (3) individual choice under ambiguity and 
(4) group choice under ambiguity, in a stochastic inter-temporal allocation problem. Groups consist of two members and decisions are made after a phase of communication and deliberation. We compare behaviour both within decision units and within decision environments. Within decision units analysis (i.e. individuals (groups) under risk vs. individuals (groups) under ambiguity) allows us to investigate whether the introduction of ambiguity, regarding the future level of income, has any significant impact to the way individuals and groups decide, while within decision environments analysis (i.e. individuals vs. groups under risk (ambiguity)), allows us to explore whether there are fundamental differences between individuals and groups.

Our main results can be summarised as follows. Both groups and individuals substantially deviate from the predicted theoretical optimal level of consumption both under risk and under ambiguity. There are significant treatment effects within a decision environment. We observe an anti-symmetric result, where individuals perform better compared to groups under risk while groups perform better under ambiguity. Likewise, individuals tend to deviate less from the conditional level of consumption when they plan under risk compared to ambiguity, while groups deviate less in an ambiguous environment rather than in a risky one. The majority of the subjects is characterised by considerably myopic (short) planning horizons. We observe a common pattern across all treatments regarding the factors that drive behaviour (e.g. repetition of the task, available wealth) as well as significant gender effects in consumption/saving choices. Finally, we observe precautionary saving behaviour with individuals saving more under ambiguity than under risk and also individuals saving more compared to groups. We argue that the observed differences in behaviour may be the consequence of different risk and ambiguity attitudes, which extends the often observed pattern in static choice experiments of groups being risk and ambiguity neutral, to a dynamic decision framework.

The paper is organised as follows. We start in section 2 by reviewing the related literature on life-cycle experiments, dynamic group choice and group decision making under ambiguity 
and discuss how our study contributes to this literature. In section 3, we present the decision task as well as the underlying theoretical model that we aim to test. We then move to the experimental design, stimuli and procedures in section 4 while in section 5 we report our results. We then conclude.

\section{Related Literature}

Many studies in the psychology literature and more recently in the economics discipline, aim to explore differences between individuals and groups in various fields. These studies usually focus on investigating how differently individuals and groups decide, compared to the predictions of some kind of rational decision theory. Kugler et al. (2012) and Charness and Sutter (2012) report extensive experimental evidence advocating the superiority of groups regarding decision making that adheres to the game theoretical predictions. When this comparison concentrates on decision making under risk and ambiguity, the main research question that is often explored, is whether individuals and groups are characterised by different attitudes towards risk and ambiguity or if being member of a group alters the individual levels of these attitudes. Baker et al. (2008) find that groups tend to make decisions that are more consistent with risk neutral preferences, Shupp and Williams (2008) using parametric structural estimations find that groups have a lower risk aversion coefficient, Masclet et al. (2009) on the contrary, find that groups opt for the safer choices, Charness et al. (2010) find that groups perform significantly better on a probability reasoning task, Zhang and Casari (2012) report that group choices are more coherent and closer to risk neutrality, Bougheas et al. (2013) find that groups take more risk than individuals, while Baillon et al. (2016) investigate behaviour in Allais paradox and stochastic dominance tasks, reporting that groups violate less often stochastic dominance but they deviated more in the Allais paradox tasks.

More recently, motivated by the extensive experimental evidence of non-neutral ambigu- 
ity attitudes (Halevy (2007), Ahn et al. (2014), Hey and Pace (2014) and Stahl (2014) among others ${ }^{1}$ ) researchers have started investigating group decision making under ambiguity (imprecise probabilities). Early studies concentrated on the effects of social interaction to ambiguity attitudes, rather than on choices by groups (see Curley et al. (1986), Keller et al. (2007), Trautmann et al. (2008) and Muthukrishnan et al. (2009)). Charness et al. (2013) show that ambiguity neutral agents are able to persuade the non-neutral ones to make joint, ambiguityneutral decisions, Keck et al. (2014) find that groups are inclined to make more ambiguity neutral decisions and that ambiguity averse individuals tend to become ambiguity neutral after they consult with their peers. Brunette et al. (2015) report that groups applying the unanimity rule are less risk averse. They found the same pattern for ambiguity but without significance. Similar work has been done by Levati et al. (2016) who test different voting rules in collective choice under ambiguity and by Lahno (2014) who examines the effects of feedback in decision making under ambiguity.

Almost all the aforementioned studies, investigate decision making in a static framework. Nevertheless, there are a few experiments that investigate collective choice in inter-temporal frameworks. Gillet et al. (2009) find that groups make qualitatively better decisions than individuals in an inter-temporal common pool environment, Charness et al. (2007) report that individuals tend to choose first-order stochastically dominated alternatives more often in a Bayesian updating experiment, Jackson and Yariv (2014) find that social planners exhibited extensive present bias in an inter-temporal common consumption stream experiment, Carbone and Infante (2014) and Carbone and Infante (2015) compared behaviour between individuals and groups in an inter-temporal life-cycle experiment under risk (objective uncertainty) finding significant deviations from the optimal planning strategy as well as significant differences between the treatments, while Denant-Boemont et al. (2016) find that groups are more patient and make more consistent decisions in collective time preferences experiment.

\footnotetext{
${ }^{1}$ See Etner et al. (2012) for a review of the theoretical models and Trautmann and van de Kuilen (2015) for a review of the experimental evidence.
} 
In order to compare behaviour in a dynamic framework, we use a decision task borrowed from the literature on saving experiments. Literature in incentivised life-cycle experiments is as early as Hey and Dardanoni (1988). A common result of life-cycle experiments is that agents systematically deviate from the theoretically optimal consumption path usually by over-consuming during the early stages of the life-cycle and under-consume later. Several different explanations have been given for this pattern ranging from dynamically inconsistent preferences that include present bias and truncated planning horizons (Ballinger et al. (2003), Carbone and Hey (2004), Carbone (2005), Brown et al. (2009)), cognitive skills (Ballinger et al. (2011)), external habits and social learning (Carbone and Duffy (2014), Feltovich and Ejebu (2014)) to debt aversion (Meissner (2015)). ${ }^{2}$ Our study contributes to the literature in the following ways. To the best of our knowledge, this is the first study to compare individual and group decision making in a dynamic framework, under risk and ambiguity. In the field of group decision making under ambiguity, in contrast to Charness et al. (2013), Keck et al. (2014) and Brunette et al. (2015) who compare groups and individual in a static framework, using a life-cycle experimental design, we report the first experiment that studies dynamic group decision making under ambiguity in a task that involves learning and updating of ambiguous beliefs. Generally the experimental literature on dynamic decision making under ambiguity (updating and learning) is very limited. At the individual decision making level there is the work by Cohen et al. (2000) and Dominiak et al. (2012) that test the Ellsberg paradox in a dynamic framework. Similarly, regarding learning under ambiguity, whilst the topic has been quite developed theoretically (see Marinacci (2002), Epstein and Schneider (2007), Epstein et al. (2010), Zimper and Ludwig (2009)) there is lack of both experimental and empirical work. A recent study by Nicholls et al. (2015) tests whether learning helps to reduce the violations of the Ellsberg paradox. Recently, Baillon et al. (2015) study the effect of learning on ambiguity attitudes in an experiment using initial public offerings on the New York Stock Exchange.

\footnotetext{
${ }^{2}$ For an extensive review of life-cycle experiments see Duffy (2014)
} 
With this study we aim to obtain some preliminary results of dynamic group choice under ambiguity where the participants obtain information during the experiment which allows them to reduce the level of ambiguity.

Finally, regarding the literature on saving experiments, although the modelling advances in the literature of choice under ambiguity have been recently exploited to theoretically analyse life-cycle decisions (Campanale (2011), Peijnenburg (2015)), there is lack of empirical evidence. We add to this literature by reporting an experimental study of life-cycle choice where ambiguity is introduced regarding the future income stream. In addition, unlike previous saving experiments that only test the effects of social influence to consumption decisions, we explicitly test how groups make similar decisions after deliberation. Our work shares similarities with Carbone and Infante (2014) who study individual choice under certainty, risk and ambiguity in a savings experiment and Carbone and Infante (2015) who study individual and group choice under risk. Nevertheless, our study is different from Carbone and Infante (2014) mainly in three points. First, we compare groups and individuals while they focus only on individuals. Second, we study 15-period lifecycles compared to their 5-period. Then, we adopt a Bayesian learning model to represent updating regarding the future states of the world, while they assume uniform distribution of income. Finally, we extend the framework of Carbone and Infante (2015) which we use as a benchmark to introduce ambiguity to the future income.

Following Charness and Sutter (2012), who claim that “Ultimately, the goal of comparing individual and group decision making is to identify the contexts and types of decisions where each is likely to work best", this study provides a framework for understanding differences between individual and group choice in a stochastic inter-temporal consumption-saving problem under ambiguity. 


\section{Theoretical Framework}

We present a simple, discrete-time, finite horizon life-cycle model of consumption and savings decisions without discounting. An agent lives for a finite number of periods $T$ and receives utility $u\left(c_{t}\right)$ from consumption $c_{t}$ at every period $t$ with $t \in\{1,2, \cdots, T\}$. At the beginning of each period $t$, the decision maker is endowed with a stochastic income $y_{t}{ }^{3}$. At each period, the agent decides how much of her available wealth to consume and how much to save, given that there is a fixed interest rate applied to the savings each period. The wealth at every period (or the cash-on-hand) include the savings up to that period plus the endowed income for the period. There is no borrowing allowed (the consumption choices should be non-negative) and there are no bequest motives (all the available wealth must be consumed by the end of the life-cycle).

The utility that the agent receives from consumption is represented by a concave, additive separable, constant absolute relative risk aversion (CARA) utility function of the following form:

$$
U\left(c_{t}\right)=\left(k-\exp \left(-\rho c_{t}\right)\right) \alpha
$$

where $c_{t}$ is the level of the agent's consumption at each period $t, \rho$ is the coefficient of risk aversion and the parameters $\alpha>0, k>0$ are scaling factors of the utility function that allow for affine transformations. In order to induce the utility function on the subjects (a conversion function from experimental currency to monetary units) during the experiment we set the following values for the parameters: $\rho=0.1, \alpha=50$ and $k=1$. The shape of the utility function is shown in Figure 1.

The objective of the decision maker is to maximise the utility obtained by the life-cycle consumption. Using the Expected Discounted Utility model, the optimisation program can be

\footnotetext{
${ }^{3}$ The income generation process is described shortly.
} 
Figure 1: Utility Function

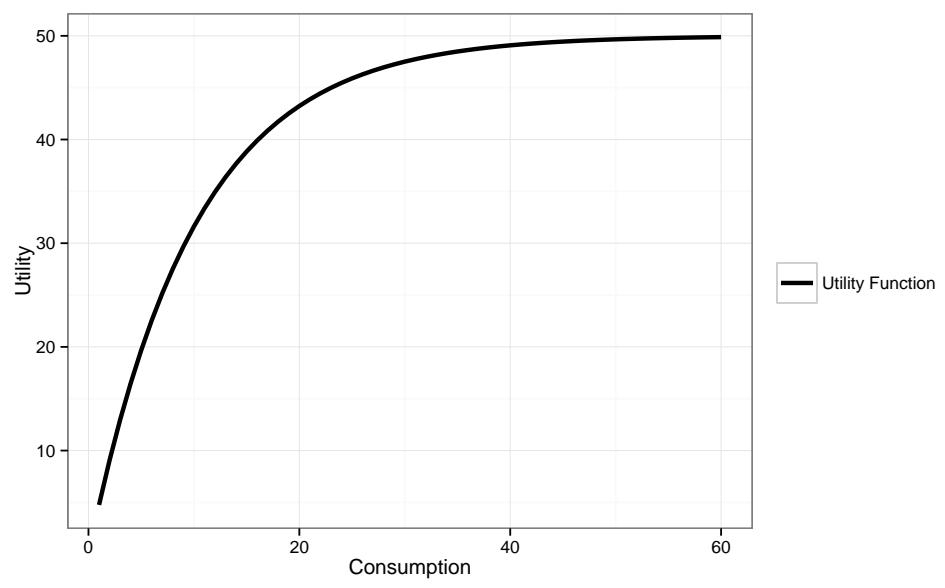

written as:

$$
\max _{\left\{c_{t}\right\}} E_{t}\left[\sum_{t=1}^{T} \beta U\left(c_{t}\right)\right]
$$

subject to the inter-temporal budget constraint:

$$
w_{t+1}=\alpha_{t+1}+y_{t}=(1+r)\left(w_{t}-c_{t}\right)+y_{t}
$$

where $w_{t+1}$ is the wealth of the next period, $w_{t}$ is the level of wealth or the cash-on-hand at the beginning of period $t, \alpha_{t+1}$ represents the available assets or savings at the beginning of period $t+1$ and $r$ is the rate of return which is known and remained constant during the experiment (at a fixed rate equal to 0.2). The discount rate is assumed to be equal to zero which means that the discount factor $\beta$ is equal to $1 . y_{t}$ represents the income of the agent at time $t$. The income follows a stochastic process which is characterised either by risk or by ambiguity and there are two possible states of the world, a state where the income is High $\left(\left(\bar{y}_{t}\right)\right)$ and a state with Low income $\left(\underline{y}_{f}\right)$. The stochastic process is following a Bernoulli distribution which is applied with the aid of a two-colour Ellsberg-type ${ }^{4}$ urn containing 10 black and white balls in equal proportions ${ }^{5}$ representing High and Low income respectively. At each period, a ball is

\footnotetext{
${ }^{4}$ The Ellsberg-type urns have been introduced in the literature by Daniel Ellsberg seminal paper (Ellsberg (1961)). In this paper he proposed two thoughts experiment with the scope to challenge the "sure thing principle" of the Subjective Expected Utility model (Savage (1954)) and to introduce non-neutral attitudes towards ambiguity. A significant number of experimental studies are making use of either the two-colour or the three-colour urn in order to introduce ambiguity in the lab.

${ }^{5}$ This information was only provided during the risk treatments. During the ambiguity treatments, subjects obtained no information regarding the composition of the urn and thus they were facing ambiguity. During the
} 
randomly drawn from the urn and the colour of the ball defines the state of the world (the income for that period). The sampling method is constituted of draws with replacement so that each draw will not alter the probabilities of the future events. Finally, borrowing is not allowed and therefore the wealth of the agents should be at all times greater or equal to zero. There are no bequest motives and any savings should be consumed before the end of the last period. In addition, there is lack of uncertainty regarding the planning horizon as the agents know the exact length of their life-cycle.

In order to solve for the optimal consumption-savings levels we adopt the value function iteration approach $\mathrm{i}$. The Bellman operator for this problem is given by:

$$
V_{t}\left(w_{t}\right)=u\left(c_{t}^{*}\right)+E\left[V_{t+1}\left(w_{t+1}^{*}\right)\right]
$$

where $V$ is the value function and $E$ is the expected operator which is defined as

$$
E\left[V_{t+1}\left(w_{t+1}^{*}\right)\right]=\mu V_{t+1}\left(w_{t+1}^{* H}\right)+(1-\mu) V_{t+1}\left(w_{t+1}^{* L}\right)
$$

where

$$
w_{t+1}^{* s}=(1+r)\left(w_{t}-c_{t}^{*}\right)+y^{s}
$$

with $s \in[L, H]$ for Low and High income respectively and $\mu$ being the subjective probability (belief) of the agent that the future state of the world will be High ${ }^{6}$. The value function establishes a recursive relation between consumption at every period $t$ and every future period $t+1$. Based on the assumptions above and the constraints imposed by the experimental design, it is possible to calculate an optimal inter-temporal consumption vector $c^{*}=\left(c_{1}^{*}, \ldots, c_{T}^{*}\right)$ for the agent's life-cycle, for any given level of wealth and for any given level of beliefs regarding the future state of the world. Under these assumptions there is no explicit solution thus we resort to numerical optimisation methods. Using backward induction along with the no bequest constraint (all the wealth must be consumed at the end of the life-cycle), we start from the last session they had the chance to observe draws from the urn and obtain information regarding the actual distribution. ${ }^{6}$ We elaborate on this issue later. 
period, where optimality requires the consumption of all the available wealth, and solve backwards, period by period, for any possible level of wealth. This guarantees that at any period, the Bellman equation is satisfied and the optimal consumption level at period $t$ is a function of the optimal level of consumption at period $t+1$. Furthermore, similarly to Ballinger et al. (2003), since everything in the experimental design is discrete (the income process, the consumption choices etc.) an exact solution is possible to be calculated and consequently, there is no need for approximation (interpolation). ${ }^{7}$ Then, for any given income stream, it is possible to work forward and to recover the optimal levels of consumption and savings, for any corresponding level of wealth. In Figure 2, the optimal life-cycle savings (end-of-period cash balances at the end of each period) path is shown, averaged over 50,000 simulated income streams. As expected ${ }^{8}$, the optimal path requires the agent to build a saving profile that is increasing for the first half of the life, reaches a peak at roughly the middle of the life-cycle and then the savings are following a decreasing path till everything is consumed at the last period.

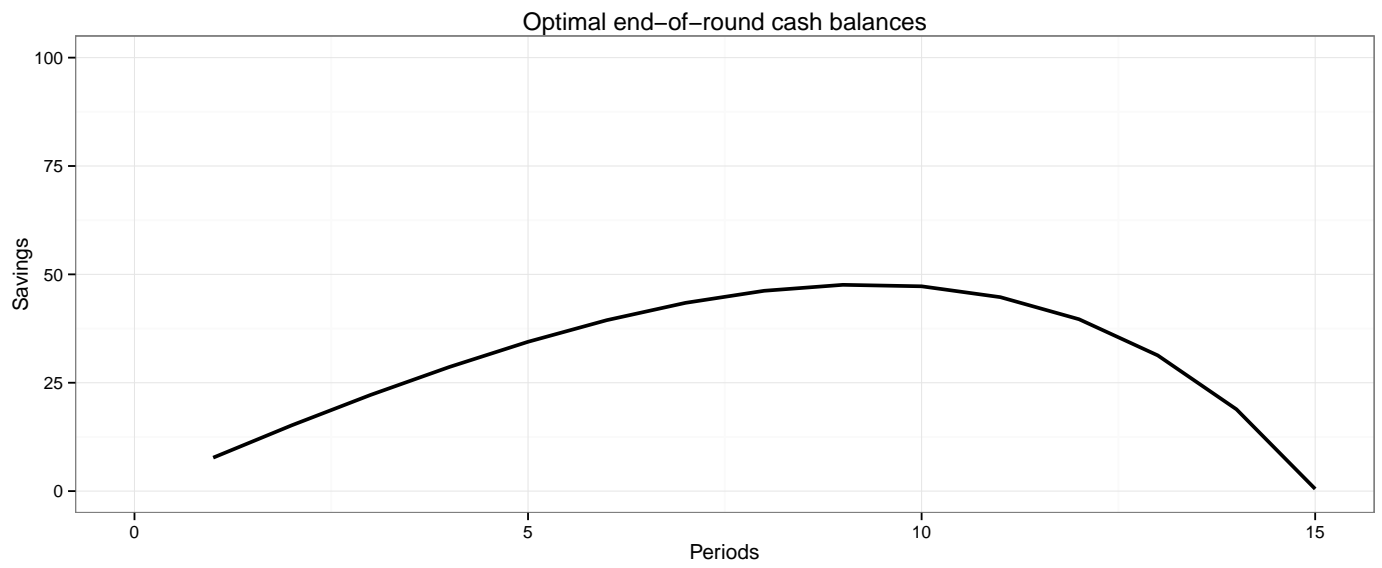

Figure 2: Optimal cash-in-hand holdings (Average of 50000 simulated income streams)

Finally, it is necessary to make some assumptions regarding the subjective beliefs $\mu$ that the agents hold on the probability of high income in a given period, how they are formed

\footnotetext{
${ }^{7}$ The optimal solution and the subsequent econometric analysis were conducted using the R programming language (R Core Team (2013)). The programs are available upon request.

${ }^{8}$ As Ballinger et al. (2003) and Feltovich and Ejebu (2014) notice, the no-borrowing constraint along with a positive third derivative of the utility function, imply motives for precautionary saving. Both conditions are satisfied in our experimental design.
} 
and how are they updated during the experiment. The exogenous income follows a simple i.i.d. Bernoulli process. Nevertheless, the subjects have no information of the value of the parameters of this distribution during the ambiguity treatments. As the income generation process involves draws with replacement, the participants have the chance to obtain information that will allow them to update their beliefs regarding the parameters that characterise the distribution. We adopt a closed-form model of Bayesian learning with additive beliefs ${ }^{9}$. We assume Subjective Expected Utility preferences for the subjects. This is done for simplification reasons as the SEU model by definition assumes neutral attitudes towards ambiguity. ${ }^{10}$ The decision maker holds some prior beliefs that are updated based on the relative frequencies that are observed from the sampling. As Zimper and Ludwig (2009) note, in this model of Bayesian learning with additive beliefs, additive posteriors converge to the same limit belief (to the true value of the distribution parameter). This model has initially appeared in the economics literature in Viscusi and O'Connor (1984) and Viscusi (1985). Briefly, the model assumes that the decision maker holds uniform priors regarding the composition of the urn, that is $\mu=\operatorname{Pr}($ High $)=\operatorname{Pr}($ Low $)=0.5$ before being able to observe any draws. Then for every draw that is being observed, the prior beliefs are updated according to the Bayes rule and the posterior belief is given by:

$$
\mu(\operatorname{High} \mid I)=\frac{1+k}{2+n}
$$

where $I$ is the available information, $k$ is the number of successes of High income and $n$ is the total number of draws that has been observed so far.

One could assume that the distribution of the balls in the urn is uniform and calculate the optimal consumption path as if the probability of high income is always equal to 0.5 and ignoring any information provided by the draws. We prefer to adopt a learning model of

\footnotetext{
${ }^{9}$ The theoretical foundations of the model are presented in Appendix A.

${ }^{10}$ Controlling for averse or loving attitudes towards ambiguity would add two additional layers of complexity to the function mapping from consumption to monetary payoffs (Carbone and Duffy (2014)). If one wants to control for attitudes towards risk and ambiguity, she needs to appropriately extend the experimental design with tasks that will perplex an already complicated decision task (see for example Hey and Dardanoni (1988)). As our main objective is to understand the effects of ambiguity to saving decisions, we leave this for future work.
} 
how beliefs are updated for two reasons. First, there is no psychological justification of why one should assume a uniform distribution and ignore all the available information. Then, as is shown in Figures 3 and 4, the learning model and the equal probabilities model, generate different optimal savings paths for a given stream of income. Figure 3 shows the two paths for an income stream where the income for at least half of the periods is High. Similarly, Figure 4 shows the path for the case of an income stream with at least half of the periods having Low income.

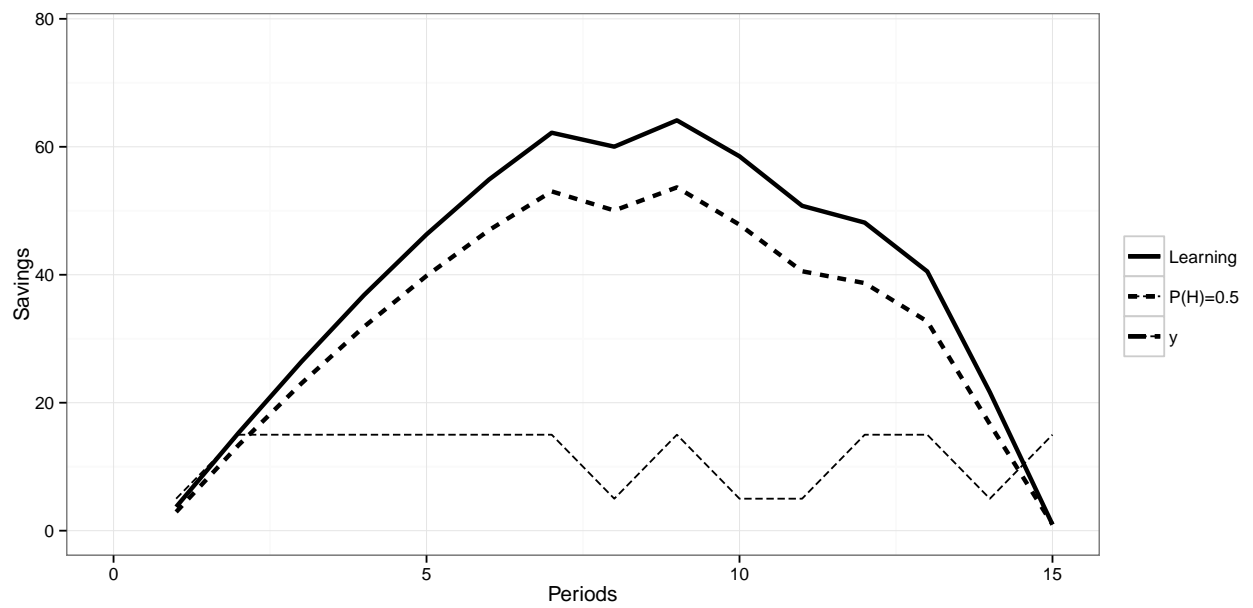

Figure 3: Learning vs. 50-50 cash-in-hand holdings (High Income Stream)

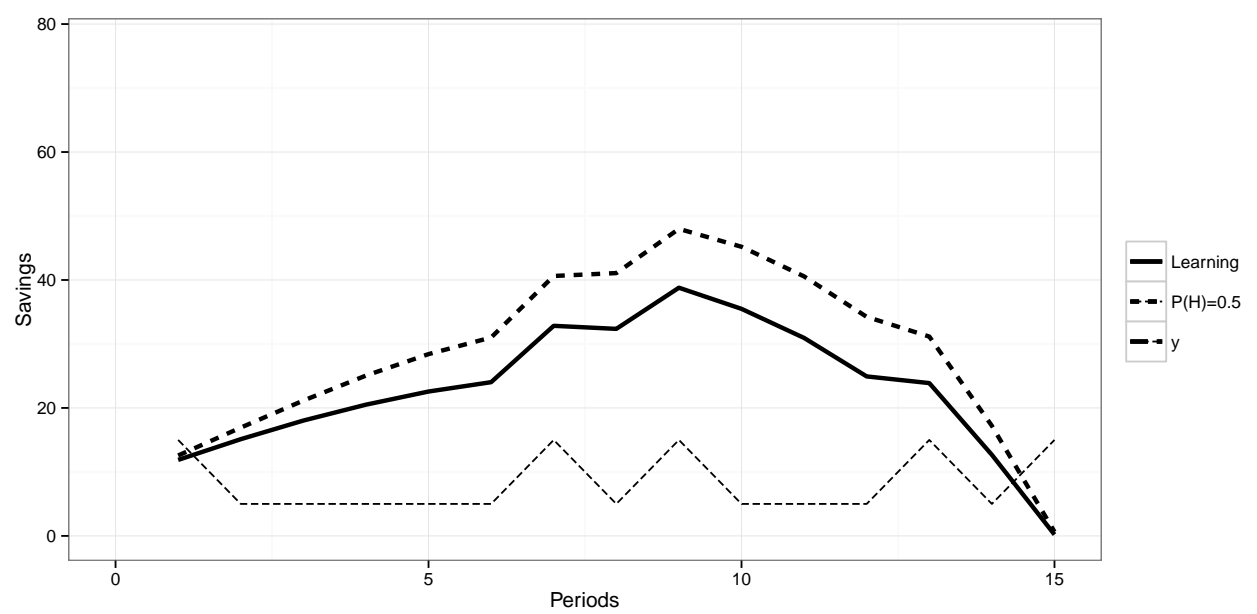

Figure 4: Learning vs. 50-50 cash-in-hand holdings (Low Income Stream) 


\section{Experimental Design and Procedures}

In order to investigate the differences between individual and group planning within the intertemporal consumption framework, we design and conduct an economic experiment using a $2 \times 2$ factorial design, with two treatment variables: decision unit (individuals vs. groups) and decision environment (risk vs. ambiguity). Therefore, the experiment features four treatments in total: individual choice under risk (I-R), individual choice under ambiguity (I-A), group choice under risk (G-R) and group choice under ambiguity (G-A).

During an experimental life-cycle (henceforth sequence) there are 15 years (periods). At each period $t$, an individual (or a group) is endowed with some income expressed in experimental currency units (tokens). This income is determined based on the process described in section 3 and can be either High $\left(\bar{y}_{t}=15\right)$ or Low $\left(\underline{y}_{t}=5\right)$. The subjects, for each period, they can choose the proportion of income that they would like to consume (they were asked to decide how many of their available tokens they would like to convert into "points"), given that the residual will be saved and earn interest at a fixed rate of return equal to 0.20 . As was mentioned before, there were no bequest motives (subjects were expected to consume the total amount of cash-on-hand at the last period of each sequence) and in addition, they could not borrow during a sequence. This task was performed twice, so each subject (or group) participated in two independent, 15-period sequences that we indicate as sequence 1 and sequence 2. Participants received written instructions that provided definitions for the meaning of sequences and periods which also clarified what was meant by "independence" of sequences ${ }^{11}$. The final payoff was determined by applying the random incentive mechanism, where one of the two sequences was randomly chosen and the accumulated consumption, transformed in monetary units at a fixed rate (two Euros per 100 points), was paid to the participants. Instructions also explained how to use the utility function (called "conversion function"), briefly

\footnotetext{
${ }^{11}$ During the experiment expressions like "income", "wealth", "consumption" or "utility" were carefully avoided.
} 
pointing out some important features, such as the property of decreasing marginal utility ${ }^{12}$. As was described in section 3, the income at each period was determined by i.i.d. draws from an urn. In the risk treatments, the subjects were told in advance that inside the urn there were 10 black and white balls in equal proportions, representing high and low income respectively. During the ambiguity treatments, the same urn was used but without providing any information to the participants regarding its actual composition. At the beginning of the experiment, one participant was asked to publicly open the urn and count the balls. When drawing a ball, participants were asked to shuffle the contents of the urn and then pick one ball to show to everyone. The ball was then placed back into the urn so as not to alter the probability of future draws. When making a decision, subjects were made aware that tokens saved would produce interest (at a fixed rate of 0.2 ) which, in the next period, would be summed to savings and income to give the total of tokens available for conversion. Instructions also explained that all variables were integers. Participants were advised that interest would be rounded to the nearest integer, and examples were given to clarify this procedure. Finally, participants were told at different points of instructions that any savings left over at the end of the last period would be worthless.

\subsection{Individual Decision Making}

In the case of individual planning (I-R and I-A), subjects were randomly assigned to computer terminals. Any contact with others, apart from the experimenters, was forbidden. For each decision participants had one minute where they could try different conversions (using a calculator), however they were not permitted to confirm their decision before the end of the time span. This procedure was implemented to induce participants to think about their strategy and reduce noise in the data. The software included a calculator to allow participants to view the consequences of their decisions (in terms of future interest, savings and utility) and to compare

\footnotetext{
${ }^{12}$ Again, there was no explicit reference to decreasing marginal utility but to "increments at a decreasing rate".
} 
alternative strategies.

\subsection{Group Decision Making}

During the group treatment (G-R and G-A) participants had to make the life-cycle decisions in pairs. Participants were randomly matched to groups at the beginning of the experiment. The identity of the members of the group was not revealed during the experiment. In the second sequence, a random matching rule was enforced, so that groups were formed at the beginning of each sequence and the same participants could not be counterparts more than once. This was implemented in an attempt to isolate the performance of groups to the greatest extent possible. As in the treatment with individuals, a strict no talking rule was imposed (with the exception of members within the group). Groups had a total of three minutes to discuss and confirm a decision; however, a choice could only be confirmed after the first minute. In order to limit the length of sessions, after the three minutes time, if no decision was confirmed by members, the computer would randomly choose between the last two proposals ${ }^{13}$. To facilitate interactions between members and increase information about group strategies, an instant messaging system was made available to chat within the group. Participants were informed about the fact that the software was recording all of their messages and that the chat system was available from the beginning to the end of each period. Participants could freely exchange messages with their counterpart but they were not allowed to reveal their identity, encourage their counterpart to share identifying information or use inappropriate language ${ }^{14}$. Instructions provided a detailed explanation of how to interact with one's counterpart and how to confirm a decision. Group members had to take turns in making proposals as well as take

\footnotetext{
${ }^{13}$ The software recorded all proposals. When members did not confirm a decision within three minutes, the computer would pick the last proposal of each member and then randomly choose one of those as representative of the group. This did not happen very frequently. We recorded 54 cases of "disagreement" out of 900 decisions $(6 \%)$. Preliminary regressions suggested that disagreement was not a significant regressor.

${ }^{14}$ The messages from the chat were restricted only to discussions regarding the levels of wealth that the participants wished to consume. Therefore, no interesting data were recovered from the chat that could help us to infer anything regarding subjects' preferences.
} 
turns as "first proposers", that is, who initiated the exchanges of proposals in a period ${ }^{15}$. The person whose turn it was to make a proposal, selected the available button labeled "Propose" which submitted it to their counterpart. After sending a proposal the turn then passed to the other group member, who had to make a counter-proposal. During this process, both members of the group had a calculator available to try different conversions and check the consequences of each of them. As mentioned above, counterparts could not confirm a group decision before one minute. For that reason, they could only use the "Propose" button; a "Confirm" button was only available after the one minute time limit. To confirm a proposal, a group member had to press the "Confirm" button; otherwise she could still make a counter-proposal and pass the turn the other member. After instructions were provided in both individual and group planning sessions, a questionnaire was distributed to test participants' understanding of the experiment. Participants were then given some time to practice with the software, in particular with the calculator and the system for group interaction. All sets of instructions included a graph of the utility function and two tables with examples of conversions and of the interest mechanism.

\subsection{Payment}

The final payoff was the conversion into money of the total of points accumulated in one sequence. The computer randomly determined which sequence would be used for payment. Instructions explained that points would be converted into money at a fixed rate of two Euros per 100 points. In the group treatments, both members of the group would receive the payoff calculated as described above. This design choice was made so as to not alter the framing of incentives between treatments. Also, the choice of not imposing a sharing rule or allowing participants to enter into bargaining on how to share the payoff, was motivated by considerations on how this might have altered the behaviour of participants during the experiment.

\footnotetext{
${ }^{15}$ In the first period of a sequence, the computer would randomly determine the "first proposer"; after that, counterparts would take turns exchanging proposals.
} 
Experimental sessions were run at two experimental economics labs in Europe, known to prohibit deception, with participants being undergraduate students of various disciplines. The experiment was programmed and conducted using the z-Tree software Fischbacher (2007).

\section{Findings}

\subsection{Deviations from Optimal Consumption}

In the literature of life-cycle experiments there have been adopted two different definitions of optimality, the unconditional and the conditional level of consumption and savings (see Ballinger et al. (2003) and Carbone and Hey (2004)). The unconditional optimal path is given by the optimal consumption vector $c^{*}$ which is calculated based on the assumptions regarding the agent's preferences, the values of the respective parameters, the income stream and the optimal level of wealth (given that all past consumption decisions were optimal). This definition of optimality is quite rigid and if an agent deviates from the optimal path at a given period, there is no way to converge to the optimal path in the future. The conditional optimal solution provides a more behaviourally plausible definition of optimality, as the optimal consumption path is calculated based on the actual available cash-on-hand (gross returns from savings of previous periods plus the endowment income $y$ of that period) that a given subject has at the beginning of every period. In addition, this approach incorporates a measure of learning effects and improvement of choices along the life-cycle. For a given period $t$ of the life-cycle, the decision maker is solving a reduced horizon problem of length $T-t+1$ based on the available cashon-hand that she has at the beginning of period $t$. At each period $t$ we calculate the conditional optimal level of consumption given the actual level of the cash-on-hand holdings. Following this approach, the conditionally optimal consumption vector ${\tilde{c_{i}}}^{*}$ is calculated which is unique for every subject $i$. We therefore adopt the definition of conditional optimality upon which we 
base all the results presented below.

We have data from 170 participants (28 subjects in the I-R treatment, 26 subjects in the I-A, 28 groups in the G-R and 30 groups in the G-A) and each subject could only participate in one session. As a basic test of understanding, we expected all subjects/groups to consume all of their wealth during the last period of each sequence. Indeed, the vast majority of the participants passed this rationality test and we consequently excluded from our sample some outlier subjects that left in their saving accounts more than 9 units. ${ }^{16}$

Finding 1 Both individuals and groups tend to systematically over-consume both under risk and under ambiguity compared to the predicted conditional optimal level of consumption.

Evidence for this finding can be found in Figure 5. Figures 5a and 5b show the periods of overconsumption/underconsumption concerning the treatments under risk, for sequences 1 and 2 respectively, while Figures $5 c$ and $5 d$ present the same information for the treatments under ambiguity. In each Figure, the horizontal (vertical) axis represents the total number of periods during which a subject (or group) under-consumes (over-consumes). Points close to where the $45^{\circ}$ line intersects with the hypotenuse correspond to agents that over-consume for roughly $50 \%$ of the rounds and under-consume for the rest, while subjects that behave according to the predicted optimal solution would be represented by points on the origin. Points above (below) the line represent individuals or groups who over-consume (under-consume) for at least half of the periods. There is extensive heterogeneity regarding behaviour and as it can be seen in both Figures, the majority of subjects tends to systematically over-consume for at least 10 out of the 15 periods. The average number of periods displaying an over-consuming behaviour under risk is 9.55 (individuals) and 9.35 (groups) in the first sequence, and 10.02

\footnotetext{
${ }^{16}$ From the sample we excluded the observations of 1 subject in sequence 1 and 2 subjects in sequence 2 in the I-R treatment, 3 subjects in sequence 1 and 1 subject in both sequences in I-A, 2 subjects in sequence 2 and 1 subject in both sequences in G-R and 1 subject in sequence 1 in G-A. We verified that including in our sample the observations of the participants who although failed the rationality test, they left in their saving accounts less than 9 units, does not change quantitatively the results that we report below.
} 
Figure 5: Periods of over-consumption and under-consumption

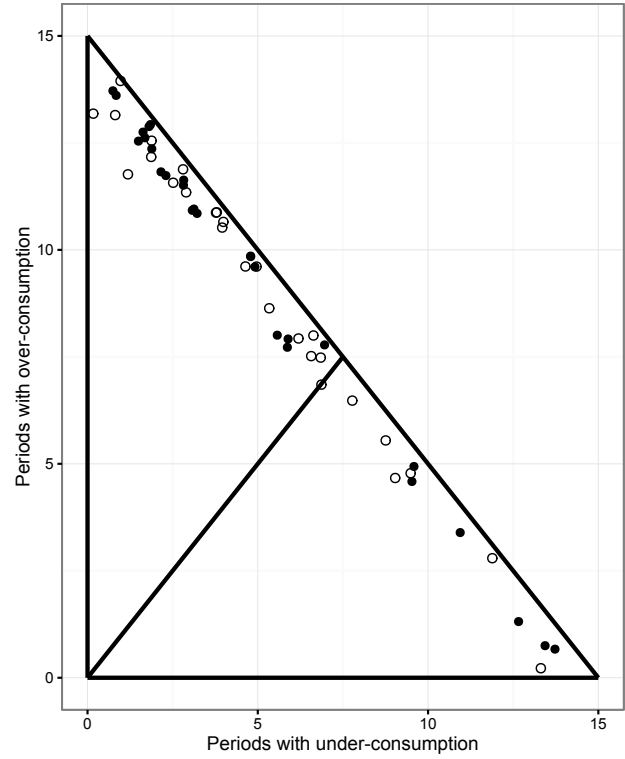

(a) Risk-Sequence 1

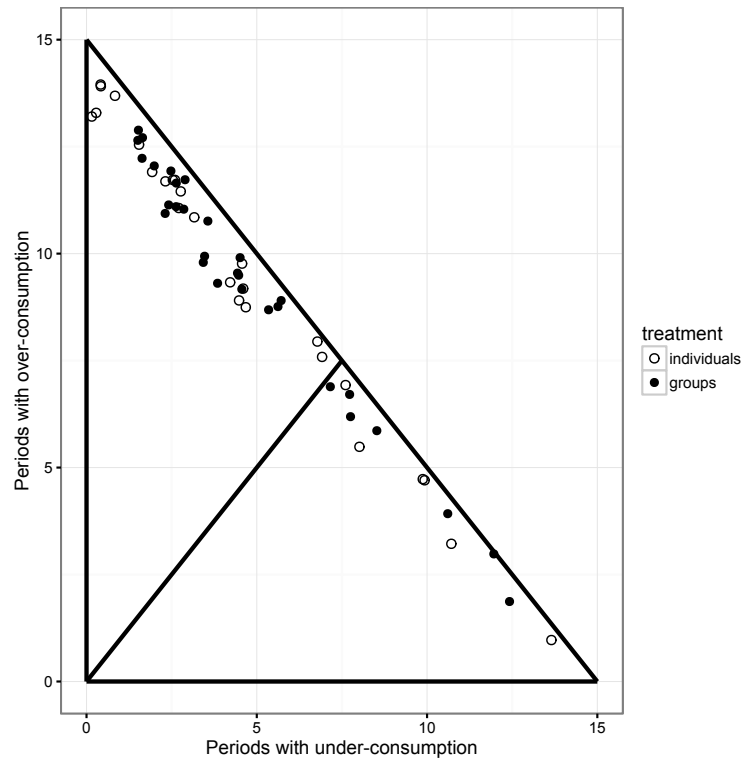

(c) Ambiguity-Sequence 1

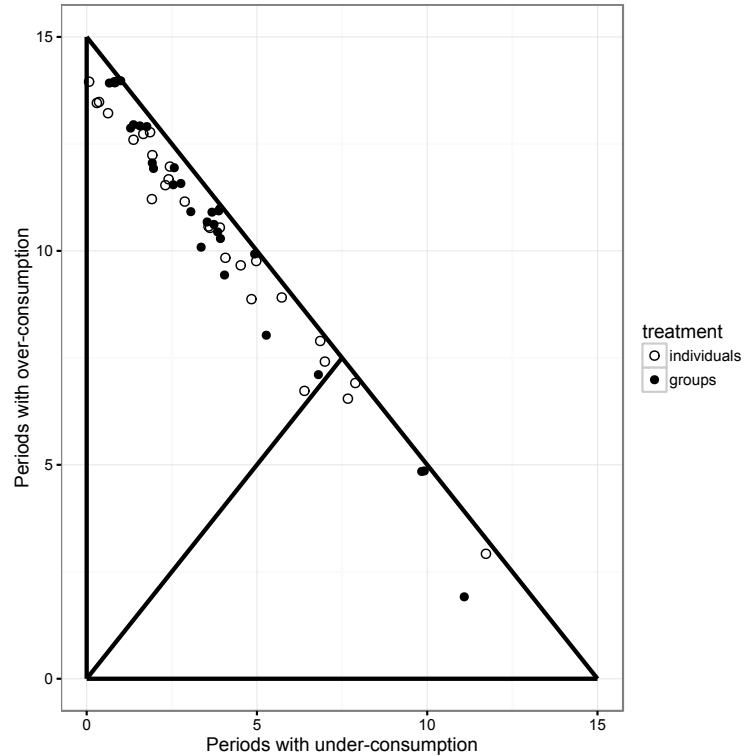

(b) Risk-Sequence 2

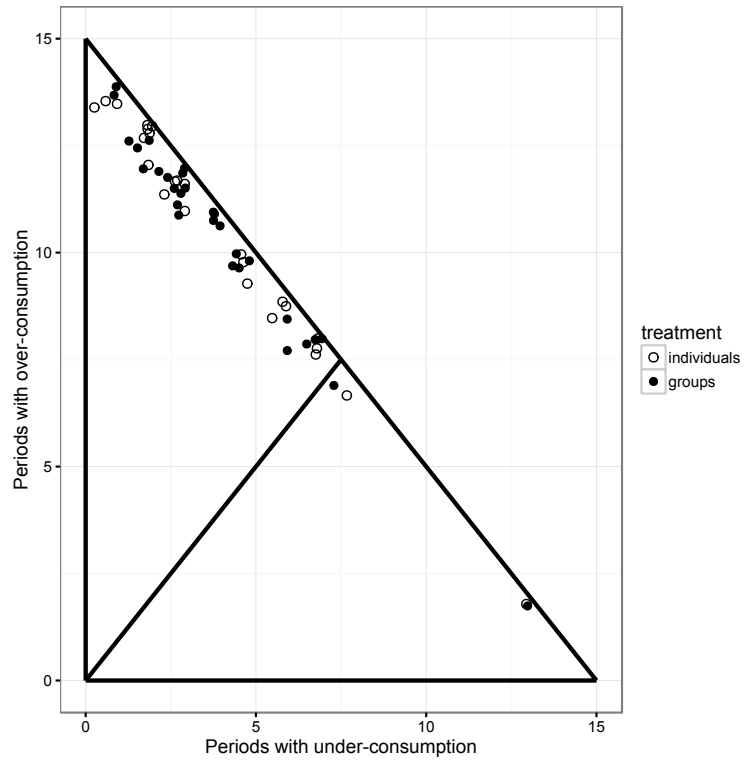

(d) Ambiguity-Sequence 2

(individuals) and 10.40 (group) in the second one. The respective number of periods for the ambiguity treatments are 9.20 and 9.25 for individuals and groups during the first sequence and 10.46 and 10.51 during the second. Figures $5 \mathrm{~b}$ and $5 \mathrm{~d}$ visually confirm this amplified overconsumption pattern during the second sequence.

Finding 2 Both groups and individuals substantially deviate from the predicted conditional optimal 
level of consumption both under risk and under ambiguity.

Figure 6 depicts the mean absolute deviation of the actual consumption choices $c$ observed in the experiment from the conditional optimal $\left(\left|c_{t}^{*}\left(w_{t}\right)-c_{t}\right|\right)$, in every period, of the 15-period sequences, for both individuals and groups. Figures $6 \mathrm{a}$ and $6 \mathrm{~b}$ illustrate the deviations of individuals and groups for the risk treatments, for sequences 1 and 2 respectively, while Figures $6 \mathrm{c}$ and $6 \mathrm{~d}$ communicate the same information concerning the ambiguity treatments. The horizontal axis represents the periods of each sequence while the vertical axis the absolute deviation. The observations of a subject who never deviates from the optimal would coincide with the horizontal axis. From the Figures, it is apparent that there are clearly systematic differences between decision units within each decision environment regarding how much they deviate from the conditional optimal. First, both individuals and groups, in both decision environments and for the two sequences, begin by significantly deviating from the optimal level. On top of that, the average deviation has a positive sign, confirming the pattern of finding 1 , highlighting subjects' difficulties to adopt a saving strategy that builds up for the first half of the sequence $^{17}$. Focusing on the risk treatments, individuals seem to significantly deviate more compared to groups during the first sequence, a pattern which is later reserved during the second sequence. In the ambiguity treatments the pattern of behaviour is less clear for the first half of each sequence. Nevertheless, the gap between individuals and groups dramatically widens since groups substantially reduce their deviation from the optimal on the one hand, while individuals steadily increase theirs, during the last half of each life-cycle.

These different patterns call for a more formal comparison between treatments. To this end, we conduct a series of generalised least squares (GLS) random effects regressions with robust standard errors clustered at the individual level (similarly at group level for groups). We run regressions both within treatments in an effort to understand how different factors affect deviations from optimum, as well as between treatments in order to identify potential treatment

\footnotetext{
${ }^{17}$ Individuals (groups) exhibit positive deviation of 4.32 (2.62) consumption units under risk and deviation of 2.56 (3.17) units under ambiguity.
} 
Figure 6: Deviations of groups and individuals from conditional optimal consumption

(a) Risk-Sequence 1

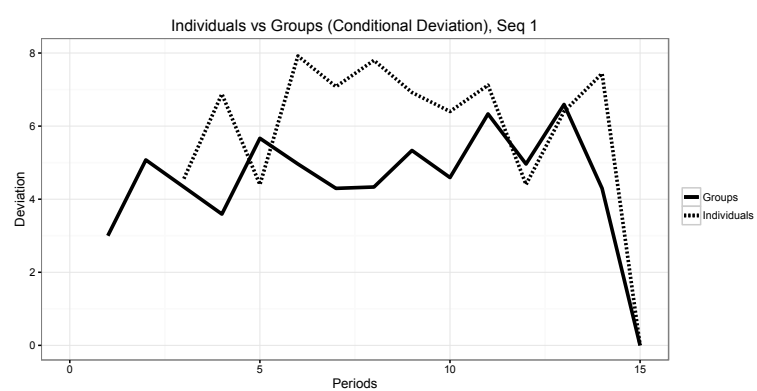

(c) Ambiguity-Sequence 1

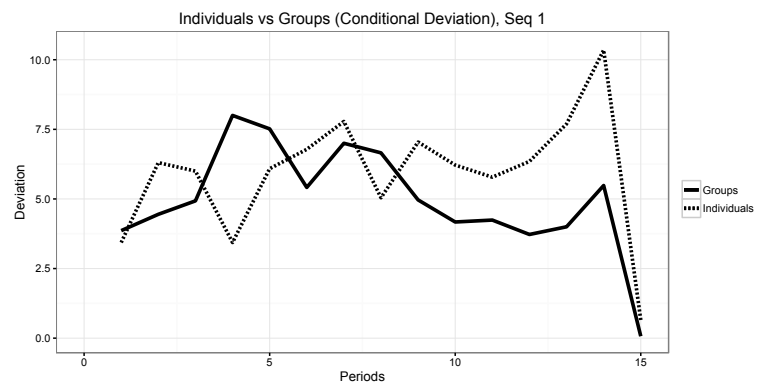

(b) Risk-Sequence 2

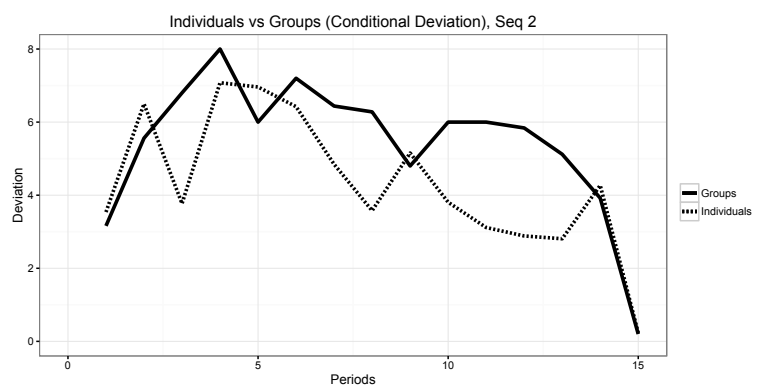

(d) Ambiguity-Sequence 2

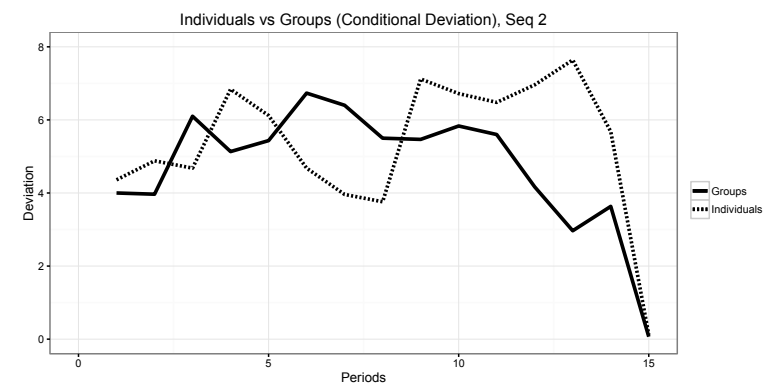

effects (both between individuals and groups and between risk and ambiguity). We first focus on the risk treatments. As dependent variable we use the conditional absolute deviation from the optimum ${ }^{18}$. The advantage of using absolute deviations is that the sign of the estimated coefficients can be interpreted as an indicator of the "direction" of the effect (i.e. a positive (negative) sign indicates increasing (decreasing) deviation from optimum). The first two columns of Table 1 report the results of regressions within the risk treatments, for individuals and groups respectively. In addition to a constant term, we include as explanatory variables the following: "period" which refers to the period number and captures the time trend, "seq2" which is a dummy variable indicating whether consumption decision was made during the second sequence, "income" which is the income the subjects received in each period, "wealth" which refers to the level of cash-on-hand at the beginning of period $t$, "gender", a dummy variable indicating of whether the subject is male, "gndrmx", a dummy variable indicating whether the

\footnotetext{
${ }^{18}$ We also conducted the regressions using the mean squared deviation from the conditional optimal as dependent variable. Although the results are magnified compared to those where absolute deviation has been used as the dependent variable, the qualitative results regarding the treatment effects remain the same. We report the results of these regressions in the supplementary material.
} 
group was formed by a heterogeneous pair ${ }^{19}$.

The constant term is positive and significantly different from zero. This term captures the deviation from the unconditional optimal at the beginning of the life-cycle $t=1$ and the statistical significance confirms the hypothesis that both individuals and groups have difficulties in calculating the optimal consumption path. The coefficient of the sequence is not significantly different from zero for individuals implying that there is no effect from the experience of the first sequence in improving behaviour. On the contrary, this coefficient is significant and positive for groups indicating a further deviation from the conditional optimal in the second sequence. The rest of the explanatory factors seem to explain behaviour in a symmetric way for both individuals and groups. The coefficient of the time trend is significant and negative, showing that there is reduction to the deviations as subjects make choices towards the end of the sequences. Income plays a positive role as does wealth, indicating that an increase to either of these two measures, leads to further deviations from the optimum. Finally, there seem to be significant gender effects, where male subjects deviate less in the individual treatment while the same is true when heterogeneous groups are asked to make choices.

We then pool together the data from the I-R and G-R treatments to test whether there is a difference between individuals and groups. We estimate the model using the same explanatory variables with the only difference that we drop the "seq2 and we introduce the dummy variable "treatg" which indicates whether a decision was made by a group. In addition, we use the following control variables: "treatg $\times$ wealth", "treatg $\times$ period" and "wealth $\times$ period" which capture the interactions between treatment, wealth and period as well as their joint interaction. The results are reported in the third column of Table 1. Not surprisingly, the signs of the explanatory variables remain the same compared to the I-R and G-R treatments alone. Furthermore, the coefficient that captures the treatment effect is positive and statistically significant. This confirms that there is significant difference between individuals and groups and

\footnotetext{
${ }^{19}$ In the case the group consisted of one male and one female member, this dummy variable takes the value 1.
} 
moreover, individuals seem to make choices that are closer to the benchmark. Also, all the interaction terms are significantly different from zero.

Table 2 reports the estimation of a similar set of regressions using the data from the ambiguity treatments. The first column includes the estimates for the I-A treatment, the second for the G-A and the third the coefficients of the the pooled I-A and G-A model. A similar pattern is observed in the within estimations as before. The main difference is that now the coefficient of the sequence is positive and significant for the individuals (compared to groups in the risk treatments) indicating a further deviation from the optimal during the second sequence. The same coefficient for the groups is statistically insignificant, implying no changes to the way the choices were made. The rest of the variables explain behaviour similarly to the risk treatments. In contrast to the risk treatments, focusing now on the pooled model (third column of Table 2), there is a significant and negative treatment effect coefficient, confirming that groups deviate less under ambiguity compared to individuals. It also worth's noting the magnitude of this treatment effect which in absolute terms, it is roughly four times bigger compared to the treatment effect in the risk treatments (-3.786 vs. 0.872$)$. We summarise the results of the regressions in the following findings:

Finding 3 Subjects significantly deviate from the conditional optimal path in both risk and ambiguity treatments. This deviation depends positively on the wealth and the income and negatively on the stage of the life-cycle. Groups improve their performance under risk while individuals worsen theirs under ambiguity during the second sequence. There are also significant gender effects with male and mixed groups deviating less from the conditional optimal.

Finding 4 There are significant treatment effects between treatments within a decision environment. Individuals perform better compared to groups under risk while groups perform better under ambiguity.

We proceed by asking the question of whether there are any differences when the same decision unit makes choices in different decision environments. That is to say, we are interested 
to find out whether the introduction of an ambiguous decision environment has significant effects to the way individuals and groups choose. To this end, we pool the together the data from I-R and I-A treatments for individual choice and from G-R and G-A for groups. Table 3 reports the estimated coefficients for the two models where the same explanatory variables as before have been used. Note that the "treatg" variable has now been substituted by "treata", a dummy variable that indicates whether a choice was made in an ambiguous environment. The first column compares individuals under risk and ambiguity with the main variable of interest being "treata". This variable in the pooled I-R and I-A model, has a significant and positive value, indicating that individuals perform much worse in the ambiguity treatment compared to the risky one, implying that ambiguity has indeed significant effects on choices. On the contrary, as can be seen in the second column of Table 3, when we compare groups under risk and ambiguity, the treatment coefficient is significant and negative, implying that groups are much better planners under ambiguity rather than under risk. The effect of all the remaining explanatory variables remains the same as above.

Finding 5 Individuals tend to deviate less from the conditional level of consumption when they plan under risk compared to ambiguity. On the contrary, groups deviate less in an ambiguous environment rather than in a risky one. 
Table 1: pooling effects regression estimates between actual and conditional optimal consumption (absolute deviation)

\begin{tabular}{|c|c|c|c|}
\hline & Treatment I-R & Treatment G-R & Treatments I-R \& G-R \\
\hline \multirow[t]{2}{*}{ (Intercept) } & $3.085^{* * *}$ & $2.422^{* * *}$ & $2.035^{* * *}$ \\
\hline & $(0.123)$ & $(0.119)$ & $(0.237)$ \\
\hline \multirow[t]{2}{*}{ seq2 } & -0.005 & $0.991^{* * *}$ & \\
\hline & $(0.068)$ & $(0.100)$ & \\
\hline \multirow[t]{2}{*}{ period } & $-0.296^{* * *}$ & $-0.313^{* * *}$ & $-0.158^{* * *}$ \\
\hline & $(0.005)$ & $(0.008)$ & $(0.023)$ \\
\hline \multirow[t]{2}{*}{ income } & $0.191^{* * *}$ & $0.088^{* * *}$ & $0.131^{* * *}$ \\
\hline & $(0.003)$ & $(0.004)$ & $(0.009)$ \\
\hline \multirow[t]{2}{*}{ wealth } & $0.152^{* * *}$ & $0.174^{* * *}$ & $0.238^{* * *}$ \\
\hline & $(0.001)$ & $(0.001)$ & $(0.013)$ \\
\hline \multirow[t]{2}{*}{ gndrm } & $-1.829^{* * *}$ & $-1.191^{* * *}$ & $-1.255^{* * *}$ \\
\hline & $(0.042)$ & $(0.057)$ & $(0.181)$ \\
\hline \multirow[t]{2}{*}{ gndrmx } & & $-1.675^{* * *}$ & $-1.902^{* * *}$ \\
\hline & & $(0.056)$ & $(0.225)$ \\
\hline \multirow[t]{2}{*}{ treatg } & & & $0.872^{* *}$ \\
\hline & & & $(0.328)$ \\
\hline \multirow[t]{2}{*}{ treatg $\times$ wealth } & & & $-0.073^{* * *}$ \\
\hline & & & $(0.019)$ \\
\hline \multirow[t]{2}{*}{ treatg $\times$ period } & & & $-0.203^{* * *}$ \\
\hline & & & $(0.032)$ \\
\hline \multirow[t]{2}{*}{ period $\times$ wealth } & & & $-0.009^{* * *}$ \\
\hline & & & $(0.001)$ \\
\hline \multirow[t]{2}{*}{ treatg $\times$ period $\times$ wealth } & & & $0.010^{* * *}$ \\
\hline & & & $(0.002)$ \\
\hline $\mathrm{R}^{2}$ & 0.380 & 0.594 & 0.494 \\
\hline
\end{tabular}


Table 2: pooling effects regression estimates between actual and conditional optimal consumption (absolute deviation)

Treatment I-A Treatment G-A Treatments I-A \& G-A

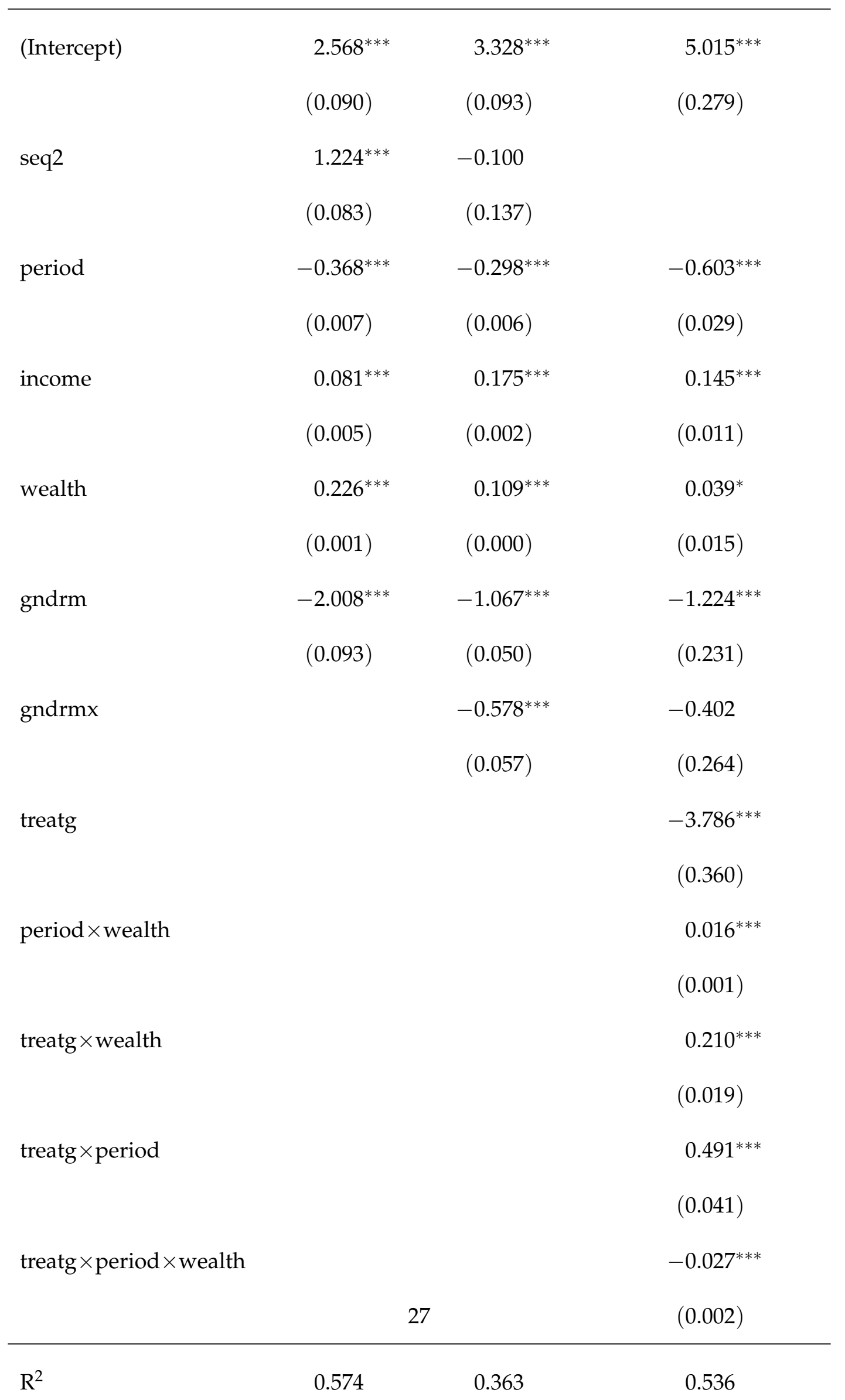


Table 3: pooling effects regressions between actual and conditional optimal consumption (comparison between decision units)

Treatments I-R \& I-A Treatments G-R \& G-A

\begin{tabular}{|c|c|c|}
\hline \multirow[t]{2}{*}{ (Intercept) } & $2.291^{* * *}$ & $2.776^{* * *}$ \\
\hline & $(0.307)$ & $(0.308)$ \\
\hline \multirow[t]{2}{*}{ tra } & $2.806^{* * *}$ & $-1.455^{* * *}$ \\
\hline & $(0.391)$ & $(0.353)$ \\
\hline \multirow[t]{2}{*}{ period } & $-0.214^{* * *}$ & $-0.382^{* * *}$ \\
\hline & $(0.028)$ & $(0.018)$ \\
\hline \multirow[t]{2}{*}{ income } & $0.147^{* * *}$ & $0.124^{* * *}$ \\
\hline & $(0.011)$ & $(0.009)$ \\
\hline \multirow[t]{2}{*}{ wealth } & $0.227^{* * *}$ & $0.160^{* * *}$ \\
\hline & $(0.013)$ & $(0.013)$ \\
\hline \multirow[t]{2}{*}{ gndrm } & $-1.275^{* * *}$ & $-1.187^{* * *}$ \\
\hline & $(0.271)$ & $(0.263)$ \\
\hline \multirow[t]{2}{*}{ period $\times$ wealth } & $-0.006^{* * *}$ & 0.001 \\
\hline & $(0.001)$ & $(0.001)$ \\
\hline \multirow[t]{2}{*}{ tra $\times$ wealth } & $-0.168^{* * *}$ & $0.100^{* * *}$ \\
\hline & $(0.019)$ & $(0.018)$ \\
\hline \multirow[t]{2}{*}{ tra $\times$ period } & $-0.412^{* * *}$ & $0.289^{* * *}$ \\
\hline & $(0.039)$ & $(0.027)$ \\
\hline \multirow[t]{2}{*}{ tra $\times$ period $\times$ wealth } & $0.021^{* * *}$ & $-0.014^{* * *}$ \\
\hline & $(0.002)$ & $(0.002)$ \\
\hline \multirow[t]{2}{*}{ gndrmx } & & $-1.042^{* * *}$ \\
\hline & & $(0.254)$ \\
\hline $\mathrm{R}^{2}$ & 0.526 & 0.498 \\
\hline Num. obs. & $1485^{28}$ & 1665 \\
\hline
\end{tabular}


The results above clearly indicate that individuals and groups behave in a substantial different way both within and between decision environments. One could argue that a potential explanation for this kind of differences is the discrepancy regarding the income streams in the various sessions. ${ }^{20}$ For instance, when we compare the I-R and G-R treatments, the further divergence from the conditional optimal could have been the consequence of a larger number of "high" income periods in the G-R treatment which induced groups to consume more. Table 4 reports the average levels of income, consumption and wealth for all treatments. Although there seem to be differences regarding the distribution of income across treatments (first column), both Mann-Whitney-Wilcoxon (MWW henceforth) and $\chi^{2}$ tests show that these differences are not statistically significant. ${ }^{21}$ Therefore, differences in the distribution of income across treatments are not sufficient to explain the observed differences.

Table 4: Average levels of income, consumption and wealth levels (standard deviations in brackets)

\begin{tabular}{cccc}
\hline Treatment & Income & Consumption & Wealth \\
\hline I-R & 9.88 & 12.36 & 23.59 \\
s.d. & $(5.00)$ & $(7.63)$ & $(10.67)$ \\
G-R & 10.16 & 13.00 & 27.25 \\
s.d. & $(5.01)$ & $(8.07)$ & $(11.73)$ \\
I-A & 9.44 & 12.03 & 25.20 \\
s.d. & $(5.02)$ & $(9.88)$ & $(13.30)$ \\
G-A & 10.08 & 12.81 & 26.03 \\
s.d. & $(5.03)$ & $(7.55)$ & $(11.05)$ \\
\hline
\end{tabular}

\subsection{Estimating Planning Horizons}

In this section, we use a bounded rationality approach and estimate the apparent planning horizons used by the subjects (see among others Ballinger et al. (2003), Carbone and Hey (2004) and Ballinger et al. (2011)), as different levels of potential myopia may be able to explain differences in behaviour. During the experiment, subjects are required to solve a complex inter-

\footnotetext{
${ }^{20}$ Note that, since during the experiment there were actual draws from the urn, there was no way to implement the same income streams to all treatments.

${ }^{21} \mathrm{I}-\mathrm{R}$ vs. G-R: $p=0.780$; I-R vs. I-A: $p=0.550$; I-A vs. G-A: $p=0.300$; G-R vs. G-A: $p=0.900$. All reported $\mathrm{p}$-values were generated using pairwise $\chi^{2}$ tests.
} 
temporal decision task and are expected to do so by employing their optimal plans using a "T-period" planning horizon, where T is equal to the 15 periods in each sequence. However, due to the complexity of the problem, some subjects tend to use simplifying rules, such as "using a shorten horizon which is then rolled forward"22" to cover the actual length of the lifecycle. As noted in Ballinger et al. (2003) and Carbone and Hey (2004), this leads to dynamic inconsistency and sub-optimal choices. In particular, a subject using this kind of strategy (having a subjective horizon of $\tau$ ) will behave in period $t$ as if period $t+\tau+1$ were the last one (except for the last period, $T$, that will be correctly recognised as the end of the life-cycle). For example, a person with two periods planning horizon, will behave as if each period is the lastbut-one, except for the last-but-one and last periods which are correctly recognised as the last two of the life-cycle. Hence, this strategy implies that in period $t$ the subject will not use the optimal consumption function (policy function) that corresponds to period $t$. Instead, she will use the consumption function of period $T+1-\tau$ if $t$ is smaller or equal to $T+1-\tau$, otherwise she will use the correct one. Following this reasoning, for each possible length of the planning horizon $\left(1 \leq \tau \leq T^{23}\right)$, the optimal solution has been computed, using the optimal consumption functions. The "apparent" planning horizon has been determined as the one in which the mean squared deviation from the optimal consumption is minimised. In other words, the "apparent" horizon is given by:

$$
\hat{\tau} \equiv \arg \min _{\tau \in\{1,2, \ldots, T\}}\left(\sum_{t=1}^{T}\left(\left[c_{t}-c_{p}{ }^{*}\right]^{2}\right)\right)
$$

where $c_{t}$ is the actual consumption of the subject for period $t$ and $c_{p}{ }^{*}$ with $p=\max \{1, t+\tau-$ $15\}$ is the optimal level of consumption based on the optimal policy function for the respective horizon that the subject is optimising. As before, we estimate the horizons using the definition of conditional optimal consumption (the consumption that would be optimal given the cashon-hand that the subject actually has in that period). Tables 5 and 6 report the average length

\footnotetext{
${ }^{22}$ Carbone and Hey (2004).

${ }^{23}$ In our experimental design, this $\tau$ may range from 1 (extreme myopic behaviour) to 15 (optimal behaviour).
} 
of the planning horizons, the standard deviation and the maximum length of the horizons for both individuals and groups, for risk and ambiguity respectively.

Table 5: Planning Horizons - Risk (Conditional Optimal)

\begin{tabular}{ccccc}
\hline & \multicolumn{2}{c}{ Individuals } & \multicolumn{2}{c}{ Groups } \\
\hline & Sequence 1 & Sequence 2 & Sequence 1 & Sequence 2 \\
\hline Average & 6.07 & 4.43 & 6.07 & 3.86 \\
s.d. & 4.20 & 2.41 & 4.42 & 2.37 \\
Max & 14.00 & 12.00 & 14.00 & 12.00 \\
\hline
\end{tabular}

Table 6: Planning Horizons - Ambiguity (Conditional Optimal)

\begin{tabular}{ccccc}
\hline & \multicolumn{2}{c}{ Individuals } & \multicolumn{2}{c}{ Groups } \\
\hline & Sequence 1 & Sequence 2 & Sequence 1 & Sequence 2 \\
\hline Average & 4.81 & 4.23 & 4.23 & 3.87 \\
s.d. & 3.97 & 3.67 & 2.65 & 2.43 \\
Max & 14.00 & 14.00 & 12.00 & 15.00 \\
\hline
\end{tabular}

Figure 7: Individual and Group Planning Horizons (Conditional Optimal)

(a) Estimated Horizons - Risk (Seq 1)

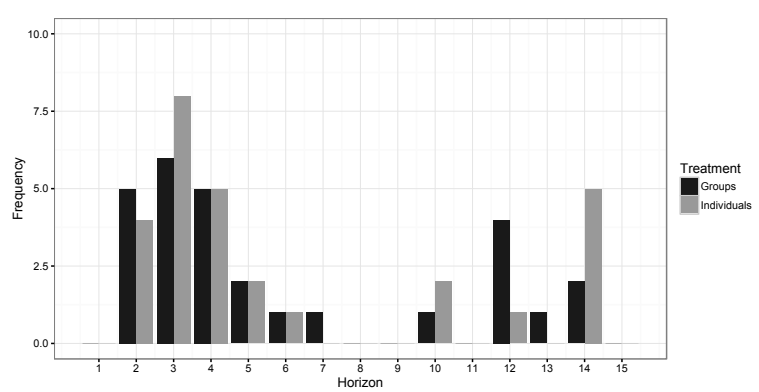

(c) Estimated Horizons - Ambiguity (Seq 1)

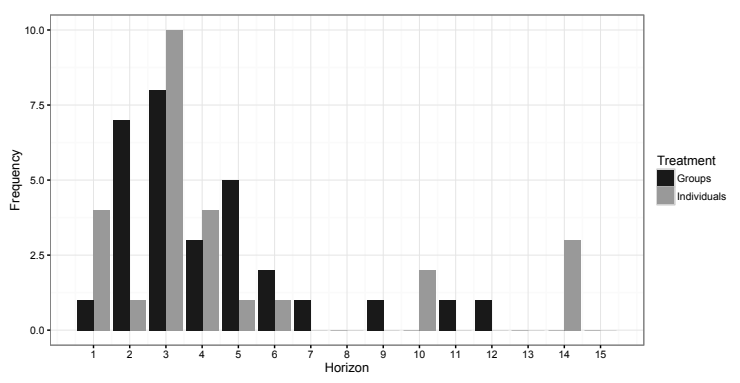

(b) Estimated Horizons - Risk (Seq 2)

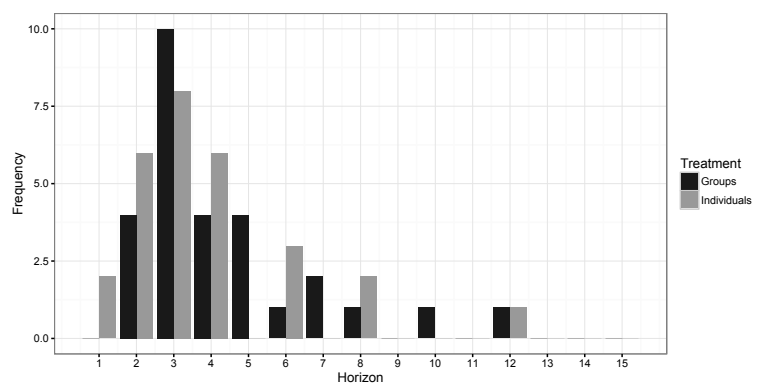

(d) Estimated Horizons - Ambiguity (Seq 2)

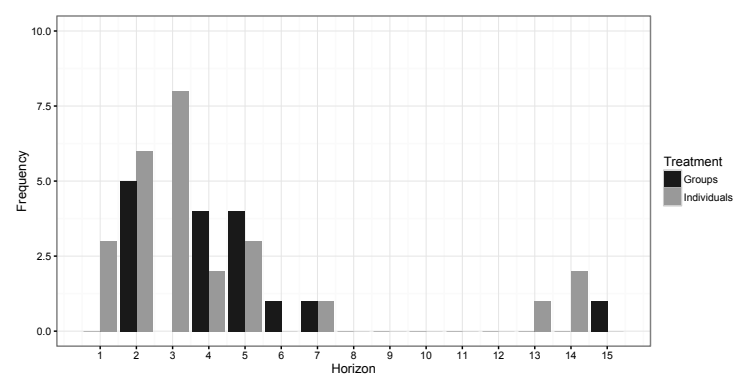

Figure 7 depicts the distribution of the estimated horizons. It is obvious from this figure that there is substantive heterogeneity between subjects. The distribution of the planning hori- 
zons is left skewed for all treatments, indicating that the majority of the subjects fail to apply a full-horizon plan for the whole life-cycle. The average planning horizon for both sequences is 5.25 (s.d.=3.31) periods for individuals and 4.97 (s.d. 3.40) periods for groups in the risk treatments and 4.52 (s.d.=3.82) for individuals and 4.05 (s.d.=2.54) periods for groups in the ambiguity treatments. At first sight, there seem to prevail two distinct patterns, that that estimated horizons in the risk treatments are longer and that both individuals and groups do not improve their planning capacity during the second sequence. Nonetheless, according to MWW tests, none of the between treatments comparisons seems to be statistically significant ${ }^{24}$, nor any of the within treatments comparisons (compare first and second sequence) appears to be different, with the exception of the I-R treatment where subjects perform significantly worst during the second period concerning their planning capacity ${ }^{25}$.

Finding 6 There is extensive heterogeneity regarding the planning horizons in all treatments. The majority of the subjects is characterised by considerably myopic (short) horizons. In addition, there are no significant differences on the length of estimated horizons across treatments.

\subsection{Precautionary Saving and Aversion towards Risk and Ambiguity}

Since neither differences in the distribution of income across treatments nor in differences regarding the planning horizons of the participants are able to explain the discrepancy in behaviour between individuals and groups, in this section we ask whether relaxing the assumption of uniform levels of risk and ambiguity neutrality as well as the uniformity of these attitudes across decision units, could explain the observed differences. We thus focus our analysis on the main variable of interest (i.e. consumption) and based on the notion of precautionary saving under risk and ambiguity (see Kimball (1990), Gollier (2001), Baillon (2016)), we aim

\footnotetext{
${ }^{24} \mathrm{I}-\mathrm{R}$ vs. G-R: $p=0.452$; I-R vs. I-A: $p=0.269$; I-A vs. G-A: $p=0.620$; G-R vs. G-A: $p=0.432$. All p-values reported were generated using rank-sum MWW tests for independent samples.

${ }^{25} \mathrm{I}-\mathrm{R}: p=0.008$; G-R: $p=0.330 ; \mathrm{I}-\mathrm{A}: p=0.178$; G-A: $p=0.743$. All reported p-values were generated using ranksum MWW tests for independent samples for the group treatments and signed-rank MWW tests for the individual ones.
} 
to understand whether different levels in consumption decisions (and consequently distinct levels of divergence) may be explained by different levels of risk and ambiguity aversion that characterise individuals and groups.

The principle of precautionary saving states that an agent who is risk averse (and therefore has a convex marginal utility, $\left.u^{\prime \prime \prime}>0\right)^{26}$ will raise the level of optimal savings in the presence of uncertainty regarding the future income. Furthermore, based on a "more prudence" argument, higher levels of risk aversion should lead to higher levels of precautionary saving and therefore, to lower levels of consumption. Given that there are no significant differences regarding the distribution of income streams across treatments, one should not expect any significant differences in the average levels of consumption as well (see Table 4). We are however able to test whether there is a difference in the level of risk aversion between individuals and groups by simply comparing their consumption decisions. Nevertheless, MWW tests reveal that these differences in consumption, are indeed significant for all but the G-R vs. G-A pairwise comparisons, indicating that the levels of risk and ambiguity aversion may be different between individuals and groups ${ }^{27}$.

To explain differences in the deviation from the optimal, we need to introduce two additional measures, namely over-consumption and under-consumption. Up to now, this deviation was measured in absolute terms. Nevertheless, as Feltovich and Ejebu (2014, footnote 15) highlight, using the absolute deviation is not a quite informative measure concerning the welfare implications of changes in the level of consumption. That is to say, an increase (decrease) in consumption when an agent over-consumes (under-consumes) is welfare-reducing (welfareenhancing) and vice-versa. The two measures that will be used as dependent variables in the

\footnotetext{
${ }^{26} \mathrm{~A}$ decision maker having a positive third derivative is said to be prudent.

${ }^{27}$ I-R vs. G-R: $p=0.025$;I-R vs. I-A: $p<0.000$; I-A vs. G-A: $p<0.001$; G-R vs. G-A: $p=0.981$. All reported $\mathrm{p}$-values were generated using rank-sum MWW tests.
} 
subsequent regressions, are defined as follows:

$$
\text { Over-consumption }= \begin{cases}c_{t}-c_{t}^{*}\left(w_{t}\right), & \text { if } c_{t} \geq c_{t}^{*}\left(w_{t}\right) \\ 0 & \text { otherwise }\end{cases}
$$

and similarly

$$
\text { Under }- \text { consumption }= \begin{cases}c_{t}^{*}\left(w_{t}\right)-c_{t}, & \text { if } c_{t}^{*}\left(w_{t}\right)>c_{t} \\ 0 & \text { otherwise }\end{cases}
$$

Using these measures, we repeat similar GLS regressions, with both over-consumption and under-consumption as dependent variables and keeping the explanatory variables similar as above. Table 7 reports the estimates of these regressions, for all the pairwise comparisons between treatments, using the over-consumption measure (similarly Table 8 for underconsumption). The main coefficient of interest is "trt" which is a dummy variable that captures treatment effects ${ }^{28}$. A positive sign of "trt" indicates a higher level of over or underconsumption.

We first focus on the differences between I-R and G-R. Groups consume on average more (13.00 (s.d.=8.07) units compared to 12.36 (s.d.= 7.63) for individuals), an indicator of higher risk aversion for individuals due to potential precautionary saving. Furthermore, in section 5.1 it was shown that groups further deviate from the conditional optimal, so one would expect that the coefficient of "trt" for over-consumption will be positive, as an increase of consumption would reduce under-consumption, as well as deviation from the optimal. Indeed, evidence from the first column in both Tables 7 and 8, confirm this hypothesis, since groups have a coefficient of over-consumption equal to 2.519. The negative sign of underconsumption (-1.569) shows that groups under-consume less. Nevertheless, the magnitude of over-consumption outweighs this effect leading to higher deviation. The comparison I-R vs. I-A is particularly interesting as it focuses within the same decision unit and hence, allows

\footnotetext{
${ }^{28}$ In each pairwise comparison, the "trt" coefficient captures the treatment effect of the second element of the pair. For instance, in the I-R vs. G-R comparison, "trt" captures the effect of the G-R treatment, in I-R vs. I-A the effect of I-A and so on.
} 
to identify the effects of introducing ambiguity to the future income. Since consumption in the I-A treatment is significantly lower compared to I-R, and given that the decision unit remains the same, one could argue that ambiguity aversion drives this result, validating the precautionary saving principle. Nevertheless, the lower consumption under ambiguity did not translate to lower deviation as well. Despite the negative coefficient of under-consumption for I-A (-0.723), a significant and positive effect of over-consumption (3.876) prevails, causing higher deviations under ambiguity. A reason for this result may be the inability of individuals to make correct judgments regarding the probability of high income, especially in the early stages of the experiment, and despite the higher savings levels, to miscalculate the optimal level of consumption, and consume at higher levels compared to those that optimality calls for. On the contrary, when we compare G-R to G-A we obtain a different result, where groups deviate less under ambiguity. The latter may confirm the finding usually observed in static choice experiments, where groups are better in probability judgment tasks compared to individuals. The lower levels of deviation can be explained by the negative coefficients of both over and under-consumption (-1.206 and -0.523 respectively) of the G-A treatment. In addition, the comparison of groups within environments, provides insights on the effects of ambiguity in consumption choices. A p-value of 0.981 indicates that there are no significant differences regarding the consumption levels of the two treatments and consequently, ambiguity aversion does not seem to have any particular effect in the levels of consumption, implying that groups have a neutral attitude towards ambiguity.

Finally, we turn to the last comparison between decision units, within the ambiguity treatments (I-A vs. G-A). Individuals now consume on average less compared to groups (12.25 (s.d.=9.88) vs. 12.81 (s.d.=7.55)). However, the reason for this potential precautionary saving from individuals is not straightforward and it may be attributed to either higher risk aversion, or higher ambiguity aversion or a combination of the two, from individuals. The lower divergence of groups, despite their higher level of consumption, is driven by both the lower levels 
Table 7: Pooling effects regression estimates (over-consumption)

\begin{tabular}{|c|c|c|c|c|}
\hline & Treatments I-R vs. G-R & Treatments I-A vs. G-A & Treatments I-R vs I-A & Treatments G-R vs. G-A \\
\hline \multirow[t]{2}{*}{ (Intercept) } & $1.878^{* * *}$ & $5.720^{* * *}$ & $3.121^{* * *}$ & $4.425^{* * *}$ \\
\hline & $(0.253)$ & $(0.285)$ & $(0.155)$ & $(0.295)$ \\
\hline \multirow[t]{2}{*}{ trt } & $2.519^{* * *}$ & $-2.173^{* * *}$ & $3.876^{* * *}$ & $-1.206^{* *}$ \\
\hline & $(0.386)$ & $(0.407)$ & $(0.190)$ & $(0.384)$ \\
\hline \multirow[t]{2}{*}{ period } & $-0.145^{* * *}$ & $-0.598^{* * *}$ & $-0.167^{* * *}$ & $-0.405^{* * *}$ \\
\hline & $(0.016)$ & $(0.026)$ & $(0.005)$ & $(0.019)$ \\
\hline \multirow[t]{2}{*}{ income } & $0.245^{* * *}$ & $0.235^{* * *}$ & $0.223^{* * *}$ & $0.239^{* * *}$ \\
\hline & $(0.009)$ & $(0.010)$ & $(0.002)$ & $(0.008)$ \\
\hline \multirow[t]{2}{*}{ wealth } & $0.154^{* * *}$ & $-0.101^{* * *}$ & $0.144^{* * *}$ & -0.025 \\
\hline & $(0.013)$ & $(0.017)$ & $(0.002)$ & $(0.014)$ \\
\hline \multirow[t]{2}{*}{ gndrm } & $-1.063^{* * *}$ & -0.185 & $-2.159^{* * *}$ & $-0.485^{* *}$ \\
\hline & $(0.138)$ & $(0.185)$ & $(0.150)$ & $(0.157)$ \\
\hline \multirow[t]{2}{*}{ gndrmx } & $-1.285^{* * *}$ & 0.085 & & $-0.479^{* *}$ \\
\hline & $(0.171)$ & $(0.211)$ & & $(0.162)$ \\
\hline \multirow[t]{2}{*}{ trt $\times$ wealth } & $-0.162^{* * *}$ & $0.114^{* * *}$ & $-0.266^{* * *}$ & $0.063^{* * *}$ \\
\hline & $(0.019)$ & $(0.022)$ & $(0.004)$ & $(0.018)$ \\
\hline \multirow[t]{2}{*}{ period $\times$ wealth } & $-0.011^{* * *}$ & $0.015^{* * *}$ & $-0.010^{* * *}$ & $0.005^{* * *}$ \\
\hline & $(0.001)$ & $(0.001)$ & $(0.000)$ & $(0.001)$ \\
\hline \multirow[t]{2}{*}{$\operatorname{trt} \times$ period } & $-0.230^{* * *}$ & $0.295^{* * *}$ & $-0.473^{* * *}$ & $0.155^{* * *}$ \\
\hline & $(0.026)$ & $(0.036)$ & $(0.007)$ & $(0.026)$ \\
\hline \multirow[t]{2}{*}{ trt $\times$ period $\times$ wealth } & $0.014^{* * *}$ & $-0.015^{* * *}$ & $0.026^{* * *}$ & $-0.007^{* * *}$ \\
\hline & $(0.002)$ & $(0.002)$ & $(0.000)$ & $(0.001)$ \\
\hline $\mathrm{R}^{2}$ & 0.228 & 0.205 & 0.213 & 0.185 \\
\hline Num. obs. & 1545 & 1605 & 1485 & 1665 \\
\hline
\end{tabular}

of over-consumption (-2.173) and that of under-consumption (-0.701) implying that groups are significantly better planners under ambiguity. As a concluding remark, we need to highlight the fact that if the subjects are actually violating the risk and ambiguity neutrality assumption, then the over and under-consumption measures are under-stated and therefore, the deviations are bound to be higher. The following findings summarise these results:

Finding 7 Between decision environments and within decision units, individuals save more under ambiguity than under risk, implying that individuals exhibit ambiguity averse attitudes. On the contrary, ambiguity has no effect to the levels of savings for groups, implying ambiguity neutral attitudes for groups.

Finding 8 Within decision environments, individuals save more under risk compared to groups, implying that individuals are more risk averse. Similarly, individuals save more under ambiguity compared to groups, implying that individuals are either more risk averse, or more ambiguity averse, or both. 
Table 8: Pooling effects regression estimates (under-consumption)

\begin{tabular}{|c|c|c|c|c|}
\hline & Treatments I-R vs. G-R & Treatments I-A vs. G-A & Treatments I-R vs I-A & Treatments G-R vs. G-A \\
\hline \multirow[t]{2}{*}{ (Intercept) } & $0.325^{* * *}$ & $-0.924^{* * *}$ & $0.330^{* *}$ & $-1.107^{* * *}$ \\
\hline & $(0.093)$ & $(0.069)$ & $(0.112)$ & $(0.143)$ \\
\hline \multirow[t]{2}{*}{$\operatorname{trt}$} & $-1.569^{* * *}$ & $-0.701^{* * *}$ & $-0.723^{* * *}$ & $-0.523^{* *}$ \\
\hline & $(0.138)$ & $(0.108)$ & $(0.161)$ & $(0.185)$ \\
\hline \multirow[t]{2}{*}{ period } & $-0.045^{* * *}$ & $0.031^{* * *}$ & -0.000 & -0.009 \\
\hline & $(0.011)$ & $(0.007)$ & $(0.011)$ & $(0.011)$ \\
\hline \multirow[t]{2}{*}{ income } & $-0.117^{* * *}$ & $-0.108^{* * *}$ & $-0.103^{* * *}$ & $-0.104^{* * *}$ \\
\hline & $(0.003)$ & $(0.002)$ & $(0.003)$ & $(0.004)$ \\
\hline \multirow[t]{2}{*}{ wealth } & $0.073^{* * *}$ & $0.160^{* * *}$ & $0.069^{* * *}$ & $0.136^{* * *}$ \\
\hline & $(0.003)$ & $(0.004)$ & $(0.004)$ & $(0.007)$ \\
\hline \multirow[t]{2}{*}{ gndrm } & $-0.408^{* * *}$ & $-0.773^{* * *}$ & $-0.869^{* * *}$ & $-0.295^{* * *}$ \\
\hline & $(0.049)$ & $(0.049)$ & $(0.062)$ & $(0.060)$ \\
\hline \multirow[t]{2}{*}{ gndrmx } & 0.076 & $-0.401^{* * *}$ & & $-0.251^{* * *}$ \\
\hline & $(0.054)$ & $(0.044)$ & & $(0.054)$ \\
\hline \multirow[t]{2}{*}{ trt $\times$ wealth } & $0.075^{* * *}$ & $0.031^{* * *}$ & $0.063^{* * *}$ & $0.042^{* * *}$ \\
\hline & $(0.005)$ & $(0.005)$ & $(0.006)$ & $(0.008)$ \\
\hline \multirow[t]{2}{*}{ period $\times$ wealth } & $0.004^{* * *}$ & $-0.002^{* * *}$ & $0.003^{* * *}$ & -0.000 \\
\hline & $(0.000)$ & $(0.000)$ & $(0.000)$ & $(0.000)$ \\
\hline \multirow[t]{2}{*}{ trt $\times$ period } & $0.051^{* * *}$ & $0.126^{* * *}$ & -0.027 & $0.158^{* * *}$ \\
\hline & $(0.015)$ & $(0.011)$ & $(0.015)$ & $(0.015)$ \\
\hline \multirow[t]{2}{*}{ trt $\times$ period $\times$ wealth } & $-0.005^{* * *}$ & $-0.007^{* * *}$ & $-0.001^{*}$ & $-0.008^{* * *}$ \\
\hline & $(0.001)$ & $(0.000)$ & $(0.001)$ & $(0.001)$ \\
\hline $\mathrm{R}^{2}$ & 0.470 & 0.418 & 0.389 & 0.506 \\
\hline Num. obs. & 1545 & 1605 & 1485 & 1665 \\
\hline
\end{tabular}

\section{Discussion and Concluding Remarks}

We present results from an intertemporal choice experiment under risk and ambiguity where we compare individual and group decision making. By introducing a stochastic income generation process, keeping the level of interest rate constant, as well as controlling the level of utility derived from consumption, we are able to calculate the optimal path of savings/consumption choices for each lifecycle and for each income history and therefore, to study deviations from optimality. We study differences both within a decision unit (i.e. individuals (groups) under risk vs. individuals (groups) under ambiguity) and within a decision environment (i.e. individuals vs. groups under risk (ambiguity)). In our analysis, we take into consideration the fact that subjects may face difficulties in successfully solving complex, stochastic problems in a dynamic environment and therefore, we adopt the definition of conditional optimal as a benchmark, which allows for mistakes at the earlier periods of the lifecycle. Our data also allows us to estimate the apparent planning horizons of the subjects, assuming a bounded rationality 
approach.

Our main findings show that (1) both individuals and groups face difficulties in detecting the optimal decision path that this stochastic, dynamic problem implies, in either environments (risk and ambiguity); (2) groups tend to deviate less from the optimal choice compared to individuals under ambiguity, while on the contrary, they deviate more in a risky environments; (3) both individuals and groups are characterised by myopic planning horizons in both environments; and (4) the introduction of ambiguity, regarding the future level of income, provokes precautionary saving effects to individuals while there is zero effect for groups.

Our results seem to be in line with the main experimental findings in the literature of savings experiments that is, people tend to overconsume in the early stages of their lives, failing to build up the required wealth for smooth consumption across the lifecycle and that subjects are characterised by rather myopic planning horizons. We contribute to this literature by showing that these results hold also in the case of ambiguity. The novelty of our experimental design, allows to directly study the effects that ambiguity, regarding the future level of income, have to dynamic decision making. Furthermore, we investigate whether there are significant differences in the way that individuals and groups decide in this particular framework. Our findings confirm the usually observed in other studies phenomenon, where groups behave closer to the predictions that some kind of rationality defines, but in our case, only for the ambiguity treatment. We argue that this may be the effect of different attitudes towards risk and ambiguity and that our results extend the pattern that is frequently observed in static choice experiments, where groups tend to be less risk and ambiguity averse compared to individuals (or stating it differently tend to behave closer to risk and ambiguity neutrality) to its dynamic dimension.

These results are of interest both from a theoretical point of view and from a public policy perspective. Despite the fact that the theoretical literature on dynamic decision making under ambiguity is well advanced, only recently these theoretical developments have been applied to model behaviour in relevant applications like lifecycle savings decisions (Campanale 
(2011), Peijnenburg (2015)). Furthermore, there is lack of empirical evidence regarding economic agents' behaviour during inter-temporal tasks, particularly in an ambiguous environment, both at individual and at group level. Although some recent studies have investigated collective choice and discounting behaviour (Jackson and Yariv (2014), Denant-Boemont et al. (2016)), the scope of this literature was to investigate preferences over time rather than to explore sequential group decision making upon the reception of new information as in our case. In this paper we have taken a first step towards understanding the effects of uncertainty regarding the future levels of income on optimal planning. From a public policy aspect, it is well established in the literature (Shapiro (2010), Carlsson et al. (2012)) that despite the various theoretical violations that groups (pairs or larger) exhibit, they tend to be more patient when making joint decisions rather than individual ones. In our study, we find that groups tend to behave closer to rationality when they plan under ambiguity, achieving in that way higher levels of welfare. This could have potential implications during the design of public policy, given that most of real-life economic decisions are taken in an ambiguous environment.

Our findings should be interpreted with some caution. As we are interested in the qualitative characteristics of inter-temporal choice under risk and ambiguity, we assume risk and ambiguity neutrality of the decision makers and we use their subsequent behaviour as our reference. The experimental design does not allow us to control for attitudes towards risk and ambiguity. A similar task would require a different design that would involve elicitation tasks (both for the attitudes and the beliefs) that would provide sufficient data in order to parametrically estimate the respective coefficients, as well as the subjective beliefs of the agents. Such a design would add additional levels of complexity to an already difficult decision task and probably would not allow us to focus on the pure effect that ambiguity has to planning, as well as to the potential differences between individuals and groups, as we are aiming to do at the current study. Despite this simplification assumption, it is a first step towards understanding the effects of ambiguity to inter-temporal consumption/savings problems. In our analysis, we 
make a speculation that the results might be driven by the existence of ambiguity non-neutral attitudes, phenomenon that is frequently observed among the standard experimental subject population. One can expect that the existence of ambiguity aversion would lead to different optimal saving and consumption decisions (e.g. precautionary saving) or that it wound intensify the observed deviations. As mentioned before, suitable adaptations are needed regarding the experimental design along with the assumed theoretical model that describes subjects' behaviour. We leave the above extensions for future work. 


\section{References}

Ahn, D., Choi, S., Gale, D., and Kariv, S. (2014). Estimating Ambiguity Aversion in a Portfolio Choice Experiment. Quantitative Economics, 5(2):195-223.

Baillon, A. (2016). Prudence with Respect to Ambiguity. The Economic Journal, forthcoming.

Baillon, A., Bleichrodt, H., Keskin, U., L'Haridon, O., and Li, C. (2015). Learning Under Ambiguity: An Experiment Using Initial Public Offerings on a Stock Market. Working paper, University of Rennes 1 \& University of Caen.

Baillon, A., Bleichrodt, H., Liu, N., and Wakker, P. (2016). Group Decision Rules and Group Rationality under Risk. Journal of Risk and Uncertainty, 52(2):99-116.

Baker, R., Laury, S., and Williams, A. (2008). Comparing Small-Group and Individual Behavior in Lottery-Choice Experiments. Southern Economic Journal, 75(2):367-382.

Ballinger, T., Hudson, E., Karkoviata, L., and Wilcox, N. (2011). Saving Behavior and Cognitive Abilities. Experimental Economics, 14(3):349-374.

Ballinger, T. P., Palumbo, M. G., and Wilcox, N. T. (2003). Precautionary Saving and Social Learning Across Generations: an Experiment. The Economic Journal, 113(490):920-947.

Bougheas, S., Nieboer, J., and Sefton, M. (2013). Risk-taking in social settings: Group and peer effects. Journal of Economic Behavior \& Organization, 92(0):273 - 283.

Brown, A. L., Chua, Z. E., and Camerer, C. F. (2009). Learning and Visceral Temptation in Dynamic Saving Experiments. Quarterly Journal of Economics, 124(1):197-231.

Brunette, M., Cabantous, L., and Couture, S. (2015). Are Individuals More Risk and Ambiguity Averse in a Group Environment or Alone? Results from an Experimental Study. Theory and Decision, 78(3):357-376.

Campanale, C. (2011). Learning, Ambiguity and Life-cycle Portfolio Allocation. Review of Economic Dynamics, 14(2):339 - 367.

Carbone, E. (2005). Demographics and Behaviour. Experimental Economics, 8:217-232. 
Carbone, E. and Duffy, J. (2014). Lifecycle Consumption Plans, Social Learning and External Habits: Experimental Evidence. Journal of Economic Behavior E Organization, 106:413 - 427.

Carbone, E. and Hey, J. D. (2004). The Effect of Unemployment on Consumption: an Experimental Analysis. The Economic Journal, 114(497):660-683.

Carbone, E. and Infante, G. (2014). Comparing Behavior Under Risk and Under Ambiguity in a Lifecycle Experiment. Theory and Decision, 57:313-322.

Carbone, E. and Infante, G. (2015). Are Groups Better Planners than Individuals? An Experimental Analysis. Journal of Behavioral and Experimental Economics, 57:112 - 119.

Carlsson, F., He, H., Martinsson, P., Qin, P., and Sutter, M. (2012). Household Decision Making in Rural China: Using Experiments to Estimate the Influences of Spouses. Journal of Economic Behavior \& Organization, 84(2):525 - 536.

Charness, G., Karni, E., and Levin, D. (2007). Individual and Group Decision Making under Risk: An Experimental Study of Bayesian Updating and Violations of First-Order Stochastic Dominance. Journal of Risk and Uncertainty, 35(2):129-148.

Charness, G., Karni, E., and Levin, D. (2010). On the Conjunction Fallacy in Probability Judgment: New Experimental Evidence Regarding Linda. Games and Economic Behavior, 68(2):551 $-556$.

Charness, G., Karni, E., and Levin, D. (2013). Ambiguity Attitudes and Social Interactions: An Experimental Investigation. Journal of Risk and Uncertainty, 46(1):1-25.

Charness, G. and Sutter, M. (2012). Groups Make Better Self-Interested Decisions. Journal of Economic Perspectives, 26(3):157-76.

Cohen, M., Gilboa, I., and Schmeidler, D. (2000). An Experimental Study of Updating Ambiguous Beliefs. Risk, Decision and Policy, 5 (2):123-133.

Curley, S., Yates, F., and Abrams, R. (1986). Psychological Sources of Ambiguity Avoidance. Organizational Behavior and Human Decision Processes, 38(2):230 - 256.

Denant-Boemont, L., Diecidue, E., and l'Haridon, O. (2016). Patience and Time Consistency in 
Collective Decisions. Experimental Economics, page forthcoming.

Dominiak, A., Dürsch, P., and Lefort, J. (2012). A Dynamic Ellsberg Urn Experiment. Games and Economic Behavior, 75:625-638.

Duffy, J. (2014). Macroeconomics: A Survey of Laboratory Research. Technical report, University of California.

Ellsberg, D. (1961). Risk, Ambiguity and the Savage Axioms. Quarterly Journal of Economics, 75:643-669.

Epstein, L., Noor, J., and Sandroni, A. (2010). Non-Bayesian Learning. The B.E. Journal of Theoretical Economics, 10(1):1-20.

Epstein, L. and Schneider, M. (2007). Learning Under Ambiguity. Review of Economic Studies, 74(4):1275-1303.

Etner, J., Jeleva, M., and Tallon, J. (2012). Decision Theory Under Ambiguity. Journal of Economic Surveys, 26(2):234-270.

Feltovich, N. and Ejebu, O. (2014). Do Positional Goods Inhibit Saving? Evidence from a Life-cycle Experiment. Journal of Economic Behavior \& Organization, 107:440 - 454. Empirical Behavioral Finance.

Fischbacher, U. (2007). z-Tree: Zurich Toolbox for Ready-made Economic Experiments. Experimental Economics, 10(2):171-178.

Gillet, J., Schram, A., and Sonnemans, J. (2009). The Tragedy of the Commons Revisited: The Importance of Group Decision-making. Journal of Public Economics, 93(56):785-797.

Gollier, C. (2001). The Economics of Risk and Time. MIT Press, Cambridge, Mass., London.

Halevy, Y. (2007). Ellsberg Revisited: An Experimental Study. Econometrica, 75(2):503-536.

Hey, J. and Pace, N. (2014). The Explanatory and Predictive Power of Non Two-StageProbability Models of Decision Making Under Ambiguity. Journal of Risk and Uncertainty, Forthcoming.

Hey, J. D. and Dardanoni, V. (1988). Optimal consumption under uncertainty: An experimental 
investigation. The Economic Journal, 98(390):105-116.

Jackson, M. O. and Yariv, L. (2014). Present Bias and Collective Dynamic Choice in the Lab. American Economic Review, 104(12):4184-4204.

Keck, S., Diecidue, E., and Budescu, D. (2014). Group Decisions under Ambiguity: Convergence to Neutrality . Journal of Economic Behavior E Organization, 103:60 - 71.

Keller, R., Sarin, R., and Sounderpandian, J. (2007). An Examination of Ambiguity Aversion: are two Heads Better than one? Judgment and Decision Making, 2(6):390-397.

Kimball, M. (1990). Precautionary Saving in the Small and in the Large. Econometrica, 58(1):5373.

Kugler, T., Kausel, E. E., and Kocher, M. G. (2012). Are Group More Rational than Individuals? A Review of Interactive Decision Making in Groups. Wiley Interdisciplinary Reviews: Cognitive Science, 3(4):471-482.

Lahno, A. M. (2014). Social anchor effects in decision-making under ambiguity. Discussion Papers in Economics 20960, University of Munich, Department of Economics.

Levati, V., Napel, S., and Soraperra, I. (2016). Collective Choices Under Ambiguity. Group Decision and Negotiation, pages 1-17.

Marinacci, M. (2002). Learning from Ambiguous Urns. Statistical Papers, 43:145-151.

Masclet, D., Colombier, N., Denant-Boemont, L., and Lohéac, Y. (2009). Group and Individual Risk Preferences: A Lottery-choice Experiment with Self-employed and Salaried Workers. Journal of Economic Behavior E Organization, 70(3):470 - 484. Field Experiments in Economics.

Meissner, T. (2015). Intertemporal Consumption and Debt Aversion: an Experimental Study. Experimental Economics, pages 1-18.

Muthukrishnan, A., Wathieu, L., and Xu, J. (2009). Ambiguity aversion and the preference for established brands. Management Science, 55(12):1933-1941.

Nicholls, N., Romm, A. T., and Zimper, A. (2015). The Impact of Statistical Learning on Violations of the Sure-thing Principle. Journal of Risk and Uncertainty, 50(2):97-115. 
Peijnenburg (2015). Life-cycle Asset Allocation with Ambiguity Aversion and Learning. Working paper.

R Core Team (2013). R: A Language and Environment for Statistical Computing. R Foundation for Statistical Computing, Vienna, Austria.

Savage, L. (1954). The Foundations of Statistics. Wiley, New York.

Shapiro, J. (2010). Discounting for You, Me and We: Time Preference in Groups and Pairs. mimeo.

Shupp, R. and Williams, A. (2008). Risk Preference Differentials of Small Groups and Individuals. The Economic Journal, 118(525):258-283.

Stahl, D. (2014). Heterogeneity of Ambiguity Preferences. The Review of Economics and Statistics, 96(5):609-617.

Trautmann, S. and van de Kuilen, G. (2015). Ambiguity Attitudes, pages 89-116. John Wiley \& Sons, Ltd.

Trautmann, S., Vieider, F., and Wakker, P. (2008). Causes of Ambiguity Aversion: Known versus Unknown Preferences. Journal of Risk and Uncertainty, 36(3):225-243.

Viscusi, W. (1985). A Bayesian Perspective on Biases in Risk Perception . Economics Letters, 17(1-2):59- 62 .

Viscusi, W. and O'Connor, J. (1984). Adaptive Responses to Chemical Labeling: Are Workers Bayesian Decision Makers? The American Economic Review, 74(5):942-956.

Zhang, J. and Casari, M. (2012). How Groups Reach Agreement in Risky Choices. Economic Inquiry, 50(2):502-515.

Zimper, A. and Ludwig, A. (2009). On Attitude Polarization under Bayesian Learning with non-additive Beliefs. Journal of Risk and Uncertainty, 39(2):181-212. 


\section{A Bayesian Learning with Additive Beliefs}

In this Appendix we provide the formal Bayesian learning model we adopt which is the benchmark model of Zimper and Ludwig (2009). We consider the income generation process applied to our experimental design where an agent is uncertain about the probability of high income $P(H)^{29}$. Nevertheless, she can observe $n$ i.i.d. draws with replacement. We define a probability space $(\mu, \Omega, \mathcal{F})$ where $\mu$ stands for the subjective additive probability measure defined on the events of the event space $\mathcal{F}$. The state space is defined as $\Omega=\Pi \times S^{\infty}$ with generic element $\omega=\left(\pi, s^{\infty}\right)$. The parameter space $\Pi$ collects all the possible values of the true probability of $(\mathrm{H})$ in any given trial. Similarly, the sample space $S^{\infty} \times_{i=1}^{\infty}\{H, L\}$ collects all the possible sequences of outcomes. It is assumed that after any given number of $n$ trials, the agent knows the result of each of the trials. In addition, it is assumed that the agent cannot somehow observe the true parameter value of the distribution. Define $\tilde{\pi}: \Omega \rightarrow[0,1]$ such that $\tilde{\pi}\left(\pi, s^{\infty}\right)=\pi$ the random variable that defines at every state the true probability of the outcome $(\mathrm{H})$. The decision maker holds priors over $\tilde{\pi}$ that are assumed to follow the Beta distribution with shape parameters $\alpha, \beta>0$. The priors are given by:

$$
\mu(\pi)=K_{\alpha, \beta} \pi^{\alpha-1}(1-\pi)^{\beta-1}
$$

with $K_{\alpha, \beta}=\frac{\Gamma(\alpha+\beta)}{\Gamma(\alpha) \Gamma(\beta)}$ and $\Gamma$ the Gamma function.

Let $X_{n}: \Omega \rightarrow\{0,1\}, n=1,2, \cdots$ denote the random variable that takes the value 1 if the income is high $(\mathrm{H})$ and zero otherwise in $n$ trials. We define as $I_{n}^{k}$ the event in $\mathcal{F}$ such that the outcome $\mathrm{H}$ has been realised $k$ times out of $n$ trials:

$$
I_{n}^{k}=\left\{\omega \in \Omega \mid I_{n}(\omega)=k\right\}
$$

Since it is assumed that the the random variable $X_{n}$ is i.i.d. Bernoulli distributed, each $I_{n}$

\footnotetext{
${ }^{29}$ The probability of low income $P(L)$ is defined as the residual $P(L)=1-P(H)$.
} 
is, conditional on the parameter-value $\pi$, binomially distributed with probabilities

$$
\mu\left(I_{n}^{k}\right)=\left(\begin{array}{l}
n \\
k
\end{array}\right) \pi^{k}(1-\pi)^{n-k} \text { for } k \in\{0, \cdots, n\}
$$

Each time that the decision maker observes a draw from the urn she receives information that allows her to update her prior beliefs. This happens with the application of the Bayes rule. The posterior that $\pi$ is the true value conditional on the information $I_{n}^{k}$ acquired till that point is given by:

$$
\begin{aligned}
\mu\left(\pi \mid I_{n}^{k}\right) & =\frac{\mu\left(\pi \cap I_{n}^{k}\right)}{\mu\left(I_{n}^{k}\right)} \\
& =\frac{\mu\left(I_{n}^{k} \mid \pi\right) \mu(\pi)}{\int_{[0,1]} \mu\left(I_{n}^{k} \mid \pi\right) \mu(\pi) d \pi} \\
& =K_{\alpha+k, \beta+n-k} \pi^{\alpha+k-1}(1-\pi)^{\beta+n-k-1}
\end{aligned}
$$

The agent's prior of the true value of the probability of $H$ is given by the expected value of $\tilde{\pi}$ with respect to the prior distribution. In the case of a Beta prior, it is possible to show that this prior is equal to:

$$
\mathbb{E}[\tilde{\pi}, \mu]=\frac{\alpha}{\alpha+\beta}
$$

where $\alpha, \beta$ are the shape parameters of the Beta distribution. During the experiment, we assume that since there is no prior information on the proportion of $H$ balls in the urn, the only reasonable prior that one can attach is 0.5 probability. Then, each draw from the urn provides the decision maker with additional information regarding the real values of the parameters of the distribution. 


\section{B Instructions - For Online Publication}

\section{B.1 Individual Decision Making}

Welcome!

This is an experiment on decision making. The experiment will last about 1 hour and a half. Please read these instructions carefully as you have the chance to earn money depending on your decisions. If you have any questions please raise your hand. The experimenter will answer in private. You are not allowed to talk to other participants in the experiment.

The experiment consists of 2 independent "sequences", each one composed of 15 periods. Sequences are independent because there is no relation between them. This means that your choices in one sequence will not influence future sequences. However, please note that, within one sequence, your decision in each period will influence subsequent periods (for example, your decision in period 1 will have consequences for period 2 and so on).

At the beginning of each period you will receive an amount of tokens that will be available to you. You have to decide how many tokens you want to convert into points. You can convert a number of tokens between 0 and the amount available to you. The conversion function of tokens to points is reported in Figure 1 (Appendix). This figure shows graphically the conversion of tokens to points in a continuous interval. You may also look at Table 1 (Appendix) where some examples of conversions are provided. Please note that that the number of points obtained from the conversion increases as the number of tokens converted increases; however, increments are realized at a decreasing rate, that is, the difference in points obtained by converting 6 tokens rather than 5 is bigger than the difference between converting 16 tokens rather than 15. Finally, please note that the more tokens are converted in each period, the less tokens 
are saved for conversion in future periods. Please note that, before period 15 (the last period) is reached, tokens not converted will be saved for the next period. Savings will earn interest, thus increasing the amount of tokens available in the following period. When period 15 (the last period) is reached, any tokens left (that is, not converted) will be worthless.

Your payoff, at the end of the experiment, will be calculated on the decisions you have made in ONE of the above mentioned "sequences". This sequence will be randomly selected among the 2 played. This means that your payment will be calculated based on the decisions you made during the 15 periods composing the randomly selected sequence. In particular, your payment will be the conversion in Euros of the total amount of points earned in the selected sequence, using a conversion rate of 2 Euros each 100 points.

$\underline{\text { Periods and Decision Making }}$

At the beginning of each period, you will be randomly assigned a number of tokens. This number may be "high" (15 tokens) or "low" (5 tokens). The probability of getting either of the two is unknown. It is important to note that the amount of tokens received in one period does not affect the chances of getting the same or the other amount in any following period. The number of tokens will be determined by a draw from a non-see-through bag containing coloured balls. There are only two colours, however the number of balls of either colour is unknown. A number of tokens (high or low) will be attributed to each of the two colours. The draw will determine the number of tokens for all participants in that period.

From period 1 to period 14, if you have any tokens saved, they will earn interest, at the rate of $20 \%(r=0.2)$. Savings plus interest accumulated will increase the number of tokens available to you in the following period. Please remember that tokens not converted at the end of pe- 
riod 15 will be worthless. Table 2 (Appendix) is available to you, reporting some examples of calculation of interest.

At the beginning of each period you will be showed on the computer screen the total of tokens available, consisting in:

1. Tokens earned in the period: 15 or 5

2. Tokens saved in the previous period (S)

3. Interest earned on savings: $\mathrm{S} \times 0.2$ (not rounded)

4. Tokens available for conversion rounded to the nearest integer (for example, $3.4=3 ; 3.5=4$ or 3.6=4): Tokens earned in the period (1.) + Tokens saved in the previous period (2) + Interest earned on savings (3.)

5. Total of points earned: sum of the points earned starting from period 1

Of course, in period 1 there will be no savings and no interest received, so the number of tokens available to you will be equal to 15 or 5 tokens.

Within this screen you will be asked to enter the number of tokens you wish to convert into points. You may change your decision in any moment before pressing the "confirm" button. When this button is pressed your decision will become irrevocable. You cannot move to the next decision before one minute from the beginning of the current period. To make your decision you may use a calculator to observe the consequences of your choice. Depending on the number entered, it is possible to see the related savings, interest earned on savings in the next period and the number of points earned from conversion. The use of the calculator will not make your choice final. 
Once the first 15-period sequence has been completed, the following sequence will start. As explained above, the experiment involves making decisions through 2 sequences.

At the end of each sequence a summary of the choices made during the 15 periods will be provided.

Earnings

When the 2 sequences have been completed, your payment will be determined. One sequence will be randomly selected and you will receive the conversion in Euros of the total amount to points earned in the selected sequence.

If you have any questions, please raise your hand and an experimenter will be happy to assist you.

Right after these instructions a short quiz testing your comprehension of the experiment will take place followed by 3 minutes practice with the conversion function. 
Appendix

Figure 1 - Conversion function

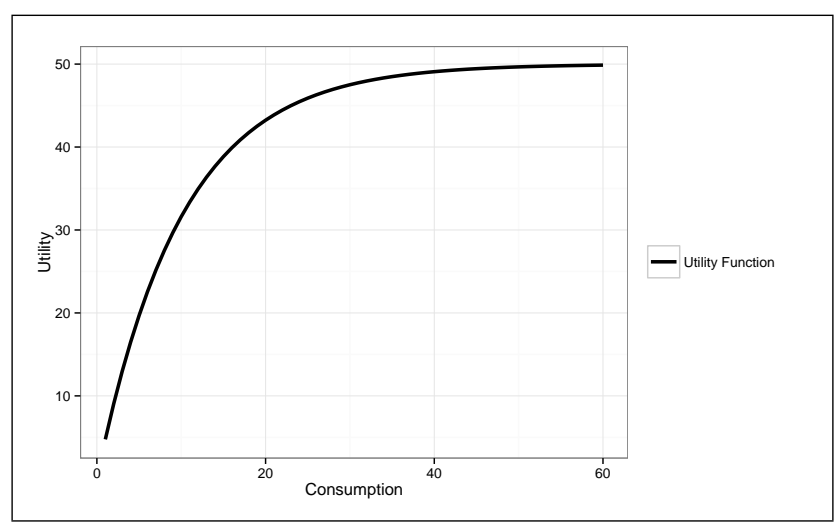




\section{TABLE 1}

\begin{tabular}{|c|c|}
\hline $\begin{array}{c}\text { Tokens } \\
\text { Converted (G) }\end{array}$ & Points Earned \\
\hline 0 & 0 \\
\hline 1 & 4.758129098 \\
\hline 2 & 9.063462346 \\
\hline 3 & 12.95908897 \\
\hline 4 & 16.4839977 \\
\hline 5 & 19.67346701 \\
\hline 6 & 22.5594182 \\
\hline 7 & 25.17073481 \\
\hline 8 & 27.53355179 \\
\hline 9 & 29.67151701 \\
\hline 10 & 31.60602794 \\
\hline 11 & 33.35644582 \\
\hline 12 & 34.9402894 \\
\hline 13 & 36.37341035 \\
\hline 14 & 37.6701518 \\
\hline 15 & 38.84349199 \\
\hline 16 & 39.9051741 \\
\hline 17 & 40.8658238 \\
\hline 18 & 41.73505559 \\
\hline 19 & 42.52156904 \\
\hline 20 & 43.23323584 \\
\hline : & \\
\hline 50 & 49.66310265 \\
\hline$\vdots$ & \\
\hline 100 & 49.99773 \\
\hline 150 & : \\
\hline 150 & 49.9999847 \\
\hline $200^{\circ}$ & 49.9999999 \\
\hline
\end{tabular}

Punti $=50-50 * e^{-0 .}$
$\mathrm{G}=$ Tokens Converted 


\begin{tabular}{|c|c|c|}
\hline \multicolumn{3}{|c|}{ TABLE 2} \\
\hline $\begin{array}{l}\text { Tokens } \\
\text { Saved }\end{array}$ & $\begin{array}{c}\text { Interest } \\
\text { on saved } \\
\text { Tokens }\end{array}$ & $\begin{array}{c}\text { Tokens } \\
\text { Saved } \\
+ \text { Interest }\end{array}$ \\
\hline 0 & 0 & 0 \\
\hline 1 & 0.2 & 1.2 \\
\hline 2 & 0.4 & 2.4 \\
\hline 3 & 0.6 & 3.6 \\
\hline 4 & 0.8 & 4.8 \\
\hline 5 & 1 & 6 \\
\hline 6 & 1.2 & 7.2 \\
\hline 7 & 1.4 & 8.4 \\
\hline 8 & 1.6 & 9.6 \\
\hline 9 & 1.8 & 10.8 \\
\hline 10 & 2 & 12 \\
\hline 11 & 2.2 & 13.2 \\
\hline 12 & 2.4 & 14.4 \\
\hline 13 & 2.6 & 15.6 \\
\hline 14 & 2.8 & 16.8 \\
\hline 15 & 3 & 18 \\
\hline 16 & 3.2 & 19.2 \\
\hline 17 & 3.4 & 20.4 \\
\hline 18 & 3.6 & 21.6 \\
\hline 19 & 3.8 & 22.8 \\
\hline 20 & 4 & 24 \\
\hline$\vdots$ & $\vdots$ & $\vdots$ \\
\hline 50 & 10 & 60 \\
\hline & $:$ & \\
\hline 100 & 20 & 120 \\
\hline : & : & $\vdots$ \\
\hline 150 & 30 & 180 \\
\hline$\vdots$ & $\vdots$ & $\vdots$ \\
\hline 200 & 40 & 240 \\
\hline
\end{tabular}




\section{B.2 Group Decision Making ${ }^{30}$}

Welcome!

This is an experiment on decision making. You will be making decisions in cooperation with another participant whose identity will be unknown to you. The experiment will last about 1 hour and a half. Please read these instructions carefully as you have the chance to earn money depending on your decisions. If you have any questions please raise your hand. The experimenter will answer in private. You are not allowed to talk to other participants in the experiment.

The experiment consists of 2 independent "sequences", each one composed of 15 periods. Sequences are independent because there is no relation between them. This means that your choices in one sequence will not influence future sequences. However, please note that, within one sequence, your decision in each period will influence subsequent periods (for example, your decision in period 1 will have consequences for period 2 and so on).

During this experiment you will be part of a group composed of two individuals. The section "Groups and Decisions" explains how groups will be formed, how to interact within a group and reach a decision.

At the beginning of each period your group will receive an amount of tokens that will be available to you. You have to decide how many tokens you want to convert into points. You can convert a number of tokens between 0 and the amount available to you. The conversion function of tokens to points is reported in Figure 1 (Appendix). This figure shows graphically the conversion of tokens to points in a continuous interval. You may also look at Table 1 (Appendix) where some examples of conversions are provided. Please note that that number of points obtained from the conversion increases as the number of tokens converted increases; however, increments are realized at a decreasing rate, that is, the difference in points obtained by converting 6 tokens rather than 5 is bigger than the difference between converting 16 tokens rather than 15. Finally, please note that the more tokens are converted in each period, the less

\footnotetext{
${ }^{30}$ The material referred to in the "Appendix" is the same for all sets of instructions and can be consulted in subsection 1 (Individual Decision Making).
} 
tokens are saved for conversion in future periods. Please note that, before period 15 (the last period) is reached, tokens not converted will be saved for the next period. Savings will earn interest, thus increasing the amount of tokens available in the following period. When period 15 (the last period) is reached, any tokens left (that is, not converted) will be worthless.

Your payoff, at the end of the experiment, will be calculated on the decisions you have made in ONE of the above mentioned "sequences". This sequence will be randomly selected among the 2 played. This means that your payment will be calculated based on the decisions you made during the 15 periods composing the randomly selected sequence. In particular, your payment will be the conversion in Euros of the total amount of points earned in the selected sequence, using a conversion rate of 2 Euros each 100 points.

Each member of the group will receive this payoff.

\section{Periods}

At the beginning of each period, you will be randomly assigned a number of tokens. This number may be "high" (15 tokens) or "low" (5 tokens). The probability of getting either of the two is unknown. It is important to note that the amount of tokens received in one period does not affect the chances of getting the same or the other amount in any following period. The number of tokens will be determined by a draw from a non-see-through bag containing coloured balls. There are only two colours, however the number of balls of either colour is unknown. A number of tokens (high or low) will be attributed to each of the two colours. The draw will determine the number of tokens for all participants in that period.

From period 1 to period 14, if you have any tokens saved, they will earn interest, at the rate of $20 \%(r=0.2)$. Savings plus interest accumulated will increase the number of tokens available to the group in the following period. Please remember that tokens not converted at the end of period 15 will be worthless. Table 2 (Appendix) is available to you, reporting some examples of calculation of interest.

Groups and Decisions 
During each sequence you will be paired with another participant but you will not know his/her identity. This matching will be random. At the end of the first sequence, of 15 periods, new groups will be composed for the second sequence, using again random matching.

Participants matched with you in a group will never have the opportunity to know your identity. During the experiment is absolutely forbidden to reveal your identity to the other group member (or try to know the identity of other participants).

At the beginning of each period you will be showed on the computer screen the total of tokens available, consisting in:

1. Tokens earned in the period: 15 or 5

2. Tokens saved in the previous period (S)

3. Interest earned on savings: $S \times 0.2$ (not rounded)

4. Tokens available for conversion rounded to the nearest integer (for example, $3.4=3 ; 3.5=4$ or 3.6=4): Tokens earned in the period (1.) + Tokens saved in the previous period (2) + Interest earned on savings (3.)

5. Total of points earned: sum of the points earned starting from period 1

Of course, in period 1 there will be no savings and no interest received, so the number of tokens available to you will be equal to 15 or 5 tokens.

In the same screen described above you will be asked to interact with the other member of your group in order to make a decision. To do this the following procedure will be employed:

1. You will have to take turns interacting with the other member

2. In the first period, one of the members of the group will be randomly selected to start the interaction. In the periods following the first, members will take turns initiating the interaction.

3. By pressing the button "PROPOSE", the member of the group who begins the interaction will send his/her proposal to the other member and conclude his/her turn. After this, 
he/she will have to wait the other member of the group to send his/her decision (accept the proposal or make a new one)

4. It will not be possible to make a group decision before 1 minute. However, during this time group members will be able to exchange proposals of conversion. At the end of the 1 minute time limit, each member of the group, during his/her turn, will also have the opportunity to confirm the proposal received, hence turning it into the group decision, which is irrevocable. The period is concluded when one of the group members confirms a proposal. Hence, the approval of the other member is not required.

5. Members will be able to keep interacting up to a time limit of 3 minutes. After this limit, if a group decision has not been made, the computer will randomly select one of the two members making his/her proposal the final decision of the group.

6. When the minimum time to make a group decision is over (1 minute), if the member whose turn it is to start interacting has not sent any proposal to his partner, the turn will automatically pass to the other member of the group.

Rules of Group Interaction

1. A group decision cannot be made before 1 minute since the start of the current period. This means that even if an agreement is reached, this decision cannot be confirmed before the minimum time limit of 1 minute is over.

2. On the screen used for group interaction, a calculator will be available to you to verify the consequences of your choice. Depending on the number of tokens entered, it is possible to see the related savings, interest earned on savings in the next period and the number of points earned from conversion.

3. A table, denominated "Group decision: current proposals" will be shown on screen. This table is composed of two rows containing the conversion proposals of each member of the group together with the related consequences. Your row is indicated by blue coloured characters.

4. Below this table a box will be available to enter your proposal of conversion, which may be confirmed by pressing the button "PROPOSE". 
5. After 1 minute, that is, the minimum time allowed to make a group decision, at each turn a button labeled "CONFIRM" will be available. By pressing this button the group decision will be recorded (becoming irrevocable)

6. An instant messaging (IM) system will also be available and operative from the beginning to the end of the period. To use the chat simply write your message and press enter on the keyboard. This way, your message will be sent to your partner. Each message will be recorded. While using the chat system it is absolutely forbidden to:

(a) Communicate one's identity in any way (name, student number, nicknames, etc.)

(b) Ask other participants questions that could lead to the disclosure of identifying information

(c) Use inappropriate language (insults, etc.)

The experimenter will make sure that all the rules of chat usage are respected. A violation of one of these rules will cause the cancellation of the final payoff of the participant who committed the violation.

When the group decision has been made, the current period ends and a new period begins.

Once the first 15-period sequence has been completed, the following sequence will start. As explained above, the experiment involves making decisions through 2 sequences.

At the end of each sequence a summary of the choices made during the 15 periods will be provided.

$\underline{\text { Earnings }}$

When the 2 sequences have been completed, your payment will be determined. One sequence will be randomly selected and you will receive the conversion in Euros of the total amount to points earned in the selected sequence.

If you have any questions, please raise your hand and an experimenter will be happy to assist you. 
Right after these instructions a short quiz testing your comprehension of the experiment will take place followed by 3 minutes practice with the conversion function and 3 minutes practice with the group-interaction system. 